\title{
Investment appraisal of cost-optimal and near-optimal pathways for the UK electricity sector transition to 2050
}

Accepted Manuscript: $1^{\text {st }}$ March 2017, Applied Energy Volume 189, Pages 89-109 doi:10.1016/j.apenergy.2016.12.047

Francis G. N. Lia , francis.li@ucl.ac.uk

Evelina Trutnevyte ${ }^{a, b}, c$, evelina.trutnevyte@alumni.ethz.ch

a University College London, UCL Energy Institute, Central House, 14 Upper Woburn Place, London, WC $1 \mathrm{H}$ oNN, United Kingdom

${ }^{\mathrm{b}}$ ETH Zurich, Department of Environmental Systems Science (D-USYS)

Transdisciplinarity Lab, Universitätstrasse 16, CHN K 76.2 CH-8092 Zurich,

Switzerland

' Swiss Competence Centre for Energy Research-Supply of Electricity (SCCER-SoE), $\mathrm{CH}-8092$ Zurich, Switzerland

(C) 2016. This manuscript version is made available under the CC-BY-NC-ND 4.0 license http://creativecommons.org/licenses/by-nc-nd/4.0/

\begin{abstract}
Deep decarbonisation of the electricity sector is central to achieving the United Kingdom's (UK) climate policy targets for 2050 and meeting its international commitments under the Paris Agreement. While the overall strategy for decarbonising the energy system has been well established in previous studies, there remain deep uncertainties around the total investment cost requirements for the power system. The future of the power system is of critical importance because low carbon electricity may create significant opportunities for emissions reduction in buildings and transport. A key policy application of quantitative analysis using models is to explore how much investment needs to be mobilised for the energy transition. However, past estimates of energy transition costs for the UK power sector have focused only on 2030 rather than 2050 and consider a relatively narrow range of uncertainties. This paper addresses this important research gap. The UK government's main whole system energy economy model is linked to a power system model that employs an advanced approach to uncertainty analysis, combining Monte Carlo simulation with Modelling-to-Generate Alternatives (MGA), producing 800 different scenario pathways. These pathways simultaneously consider uncertainties in policy, technology and costs. The results show that with No Climate Policy, installed generation capacities in 2050 are found in the range $60-75 \mathrm{GW}$, while under an $80 \%$ Reduction in GHG Emissions, between $100 \mathrm{GW}$ and $130 \mathrm{GW}$ of plant are required. Meeting climate targets for 2050 is also found to increase the investment requirements for new electricity generation. The interquartile range for cumulative investments in new generation under the No Climate Policy scenario ranges from f6obn to $175 \mathrm{bn}$, while under an $80 \%$ Reduction in GHG Emissions, investment requirements approximately double to $£ 110 b n$ - $£ 140 b n$. The exercise demonstrates the importance of uncertainty analysis to policy evaluation, yielding insights for future research practice both in the UK and internationally.
\end{abstract}




\section{Keywords}

Uncertainty analysis; energy transitions; electricity; investment appraisal; modelling to generate alternatives; decarbonization

\section{Highlights}

- 800 future transition pathways for the UK power sector explored under uncertainty

- Analysis combines Monte Carlo simulation and Modelling-to-GenerateAlternatives (MGA)

- Many technologically diverse pathways are found to incur similar overall costs

- Meeting climate targets may require an additional $25 \mathrm{GW}-70 \mathrm{GW}$ of power capacity

- Achieving climate targets may require additional investments of $£ 35 \mathrm{bn}$ f8obn

\section{Introduction: Investment needs and the key uncertainties facing the UK electricity} sector

The Paris Agreement commits signatories from 175 states to limiting anthropogenic global warming below $2^{\circ} \mathrm{C}$ above pre-industrial levels [1]. Achieving this objective will require large-scale decarbonisation of the global energy system through actions taken at the level of individual countries. Under Article 4, more developed countries are expected to take a leading role. Examples of deep decarbonisation analysis can be found for multiple countries, including China [2,3] , the United States [4], Germany [5], Denmark [6], Ireland [7] , Switzerland [8], Portugal [9] , and the United Kingdom $[10,11]$. The United Kingdom (UK) is one example of an advanced economy which is already committed to ambitious long-term decarbonisation targets. These targets are enshrined in law under the Climate Change Act 2008 [12], and are implemented as a series of carbon budgets subject to monitoring by an independent regulator [13].

Whole system analyses of long-term climate mitigation strategies for the UK that simultaneously evaluate options for buildings, industry, transport and energy supply have shown the critical role of decarbonising the UK electricity sector $[14,15]$. Most modelled UK low-carbon pathways that achieve climate targets for 2050 rely on the rapid decarbonisation of electricity generation before the 2030 in order to later electrify large fractions of building heating and road transport [16]. Model-based insights have led to the decarbonisation of the power sector and the electrification of heating and transport becoming key pillars of the UK government's greenhouse gas (GHG) emissions reduction strategy [17-19]. However, while the strategic direction of travel is clear, the level of investment costs required to mobilise the energy transition remains an important unresolved area for policymakers.

Previous analyses have evaluated the investment costs associated with a handful of potential electricity sector pathways out to the $20305[20,21]$. However, these pathways accounted for only a limited set of uncertainties and did not include an outlook to 2050 (Section 3.0). The willingness of investors to finance new low-carbon 
generation remains a major uncertainty [22]. The 2008 financial crisis left many traditional financing sources, such as banks, in a weakened state and recent "Electricity Market Reform" measures have been designed to attract investment from a wider range of financial institutions [23]. However, empirical research suggests that institutional investors are currently deterred from placing funds into low-carbon infrastructures because of the perceived high risks caused by the Government's uncertain strategic intentions [24]. It remains to be seen whether the UK's current institutional and governance arrangements will be fit for purpose and deliver the required investment levels, or whether other alternatives may need to be pursued. Research has explored market-, state- and civic-led pathways for the electricity sector [25], but it remains far from clear what the most effective governance arrangements could be to drive the desired transition.

Another key uncertainty is the timing for the commercial availability and deployment of key low-carbon generation technologies and their future costs in the period to $2050[22,26]$. For example, new nuclear power has received significant policy support in the UK, but attracting investment for the first new plant, Hinkley Point $C$, has been an extremely challenging process [27]. The UK has historically been a strong proponent of nuclear power despite vociferous opposition from various political and civil society groups [28]. Nuclear power is not the only low-carbon power technology that potentially faces deep uncertainties and an uphill struggle. Fossil-fuelled plants fitted with Carbon Capture and Storage (CCS) have been identified as key to enabling an affordable transition towards UK climate targets $[13,14,29]$. Although pilot and demonstration projects are essential for the eventual commercialisation of CCS [30,31], in 2016 the UK Government cancelled its support for a CCS demonstration programme for the second time in 5 years [32]. This again increases uncertainties about the future costs and availability of CCS in the UK.

Other key uncertainties highlighted in both expert elicitations and model-based analyses include the influence of economic growth, population demographics [26], and long-term shifts in energy demand resulting from changes to behaviour and lifestyles [33]. The costs of fossil fuels, for which the UK is a net importer, are uncertain and could be highly significant for the future transition $[15,26,34]$. The future availability of bioenergy resources is another widely-acknowledged uncertainty [35-37]. Bioenergy may be central for decarbonising many UK economic sectors such as industry, heating and transport. It could also be particularly important in electricity generation, especially when used in conjunction with CCS technology to achieve negative emissions [15]; though this is considered by many to be a controversial strategy [38].

Finally, there are large uncertainties associated with the socio-political dimension to energy policy [22]. The UK Climate Change Act enjoyed broad cross-party political support when it was implemented in 2008, but the political appetite to strive for extremely challenging climate targets has yet to be seriously tested [39]. The new administration which came into power in July 2016 has taken the step of abolishing the UK Department of Energy and Climate Change (DECC), potentially signalling that environmental issues are falling down the policy priority scale. It remains to be seen whether an electorate that can vote out unpopular governments will be willing to bear the increased and sustained costs of any future energy transition [40]. 
Deep decarbonisation of the electricity system is central to achieving the UK's climate targets for 2050. While the critical role of the power sector in enabling emissions reductions has become broadly accepted in the energy policy community, critical details for implementing this strategy such as understanding the total costs involved remain underexplored. The costs of meeting the decarbonisation challenge are subject to multiple uncertainties that make investment appraisals difficult. This study aims to review past investment analyses (Section 3.0), evaluate the current state-ofthe-art in energy modelling and uncertainty analysis (Section 4.0), and conduct an original UK electricity sector investment appraisal for the period 2010-2050 under a broad spectrum of policy, technology and cost uncertainties (Sections 5.0 and 6.0). Finally, the implications for UK and international energy policy and research into energy systems decarbonisation using quantitative models is explored (Sections 7.0 and 8.0).

3.0 Review of existing estimates of the UK electricity sector investment requirements

Before presenting our own analysis in Sections 5.0 and 6.0, we first present a review of past estimates of the investment costs required to transform the UK electricity sector. In line with earlier overviews by Blyth et al. [41] and Trutnevyte et al. [20], a range of first-order estimates for investment costs from a variety of sources is shown in Figure 1. To enable cross-comparison across different time horizons, investment costs are expressed in terms of annual capital expenditure. 
Figure 1-Existing estimates of the UK electricity sector investment requirements from various industry, academic, and government sources $[20,23,42-50]$

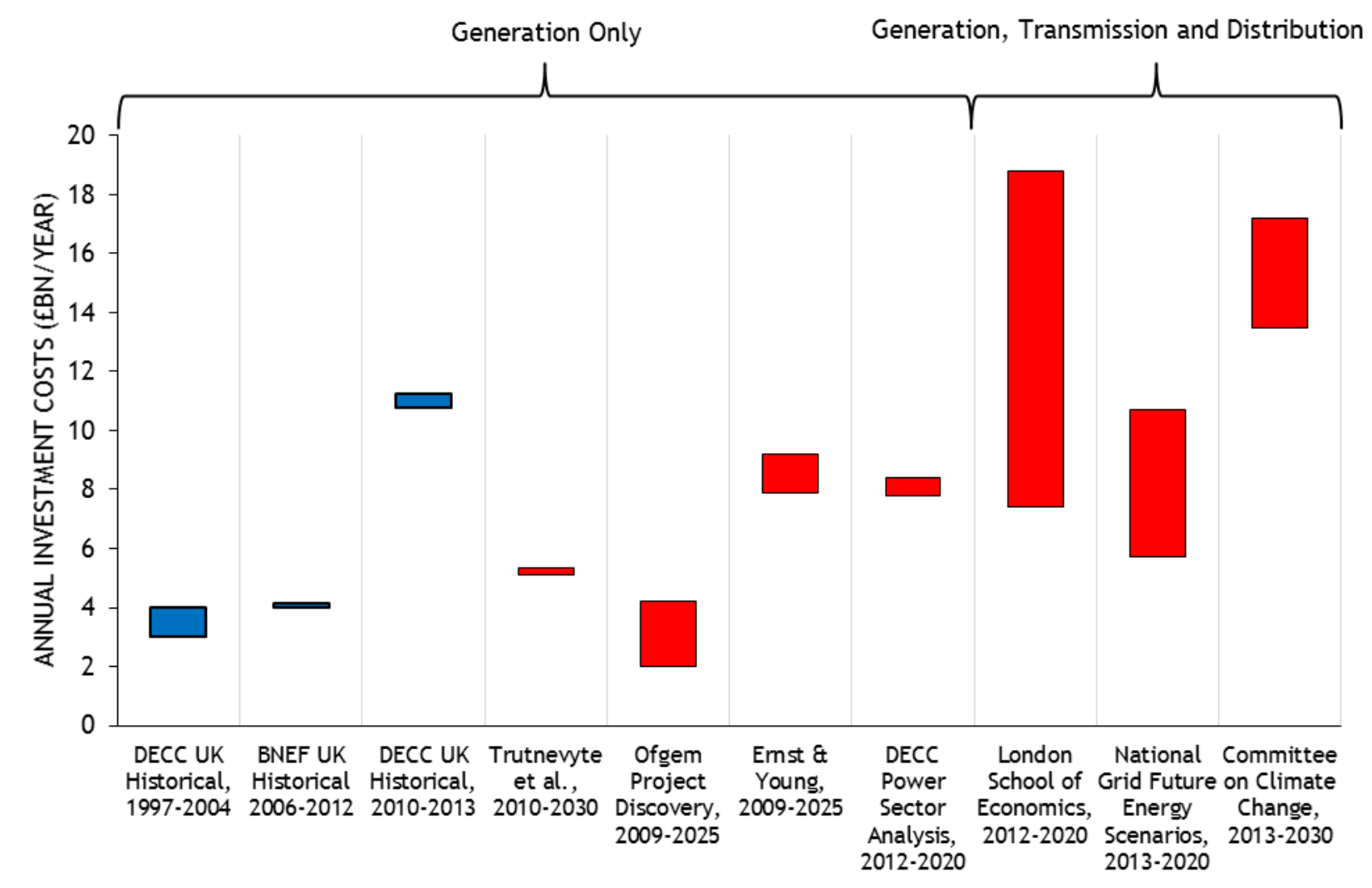

Historically, after the UK energy market liberalisation of the 1990s, investment into the power sector averaged around $£ 3-4 b n$ [20], with this rising to an average of $f 11 \mathrm{bn}$ from 2010 to 2013 [50]. Figure 1 shows that there is significant variation in the estimates of future investment requirements. This variation not only arises from the different time horizons considered, but also from differing assumptions with respect to technology-specific investment costs, electricity demand, and the future electricity generation mix. Despite the relatively large number of published estimates (Figure 1), understanding the scale of the investment challenge remains difficult. The spread of estimates is wide and it is not immediately clear where the differences come from. A cross-comparison of existing estimates is a useful starting point for discussion but does not begin to unpick the complex web of uncertainties affecting the future investment requirements. To assess these uncertainties, some of the core assumptions are compared in Table 1. 
Table 1 - Uncertainties explored in existing studies of the future UK electricity sector investment requirements

\begin{tabular}{|c|c|c|c|c|c|c|}
\hline \multirow[b]{2}{*}{ Study } & \multicolumn{6}{|c|}{ Uncertainties Explored } \\
\hline & $\begin{array}{c}\text { Restricted } \\
\text { commercial } \\
\text { availability of } \\
\text { specific } \\
\text { technologies }\end{array}$ & $\begin{array}{c}\text { Technology } \\
\text { costs and } \\
\text { project } \\
\text { finance }\end{array}$ & Fuel costs & $\begin{array}{l}\text { Energy } \\
\text { demand } \\
\text { growth }\end{array}$ & $\begin{array}{c}\text { Climate } \\
\text { target } \\
\text { stringency I } \\
\text { level of } \\
\text { policy } \\
\text { support }\end{array}$ & $\begin{array}{l}\text { Time } \\
\text { horizon }\end{array}$ \\
\hline $\begin{array}{l}\text { Trutnevyte et al. } \\
{[20]}\end{array}$ & $\checkmark$ & $\checkmark$ & $\sqrt{ }$ & $\sqrt{ }$ & $x$ & 2050 \\
\hline $\begin{array}{c}\text { Ofgem Project } \\
\text { Discovery }[43,44]\end{array}$ & $\checkmark$ & $\checkmark$ & $\checkmark$ & $\sqrt{ }$ & $\checkmark$ & 2025 \\
\hline $\begin{array}{l}\text { DECC Projections } \\
\text { [46] interpreted } \\
\text { by Blyth et al. [41] }\end{array}$ & $x$ & X & $\checkmark$ & $\checkmark$ & $\checkmark$ & 2030 \\
\hline $\begin{array}{l}\text { London School of } \\
\text { Economics [47] }\end{array}$ & $\checkmark$ & X & X & X & $\checkmark$ & 2030 \\
\hline $\begin{array}{l}\text { National Grid } \\
\text { Future Energy } \\
\text { Scenarios [21] }\end{array}$ & $\sqrt{ }$ & X & $x$ & $\sqrt{ }$ & $\sqrt{ }$ & 2035 \\
\hline $\begin{array}{c}\text { Ernst and Young } \\
\text { [48] }\end{array}$ & $\checkmark$ & X & X & $\sqrt{ }$ & X & 2025 \\
\hline $\begin{array}{l}\text { Committee on } \\
\text { Climate Change } \\
\text { [49] interpreted } \\
\text { by Blyth et al. [41] } \\
\text { using costs by } \\
\text { Pöyry [51] }\end{array}$ & $\checkmark$ & $\sqrt{ }$ & $\sqrt{ }$ & X & $\checkmark$ & 2030 \\
\hline
\end{tabular}

From a methodological perspective, the studies reported in Table 1 used scenarios accompanied by a narrative, following a "storyline and simulation" approach [52] for exploring future uncertainties. Past UK Department of Energy and Climate Change (DECC) projections [46] incorporated Monte Carlo sampling of some key inputs. Trutnevyte et al. [20] and the Ofgem Project Discovery studies [43,44] included a simple sensitivity analysis. Nearly all studies incorporated pathways with restricted availability of different low-carbon generation options, such as nuclear and CCS. Only a single study explored electricity sector pathways under conditions where bioenergy was restricted [21], although the UK Committee for Climate Change (CCC) has explored UK bioenergy availability in depth in other work [53].

Many pathways relied on static technology-specific costs for low-carbon generation technologies and did not explore uncertainties surrounding their future variation through time. Just over half of the reviewed studies explored variation in fuel costs and underlying growth in energy service demands, although only a few studies considered these elements simultaneously. Finally, most studies explored the impact of varying levels of policy support, with some explicitly considering cases involving the failure of UK climate policy (London School of Economics [47], and National Grid [21]). These studies showed wider ranges when compared with those that evaluated 
costs under pathways designed to achieve climate targets (such as Trutnevyte et al. [20]).

This review of the existing investment estimates shows that no past work has simultaneously considered the key uncertainty dimensions identified. These studies have investment estimates that diverge from both the historical experience and from each other through very different sensitivities and end points. This gives the intended policy audience a restricted view on the landscape of possible future investment requirements. Depending on which study is reviewed, the intended audience might conclude that investment requirements either need to be massively increased when compared with the past, or not to increase at all. There is therefore a need for a more systematic approach to be taken towards UK electricity sector investment appraisal in the period to 2050 .

\section{The state of the art in energy systems models and uncertainty analysis}

Energy economy models have seen long and extensive use for exploring technology pathways and the associated costs of achieving climate targets in the UK $[54,55]$ and internationally [56]. Bottom-up energy system optimisation models (ESOMs), such as TIMES [57], OSEMoSYS [58], or MESSAGE [59], are among the most popular models used for national-scale energy policy analysis and decarbonisation pathway planning. The main strength of such models is their ability to explore trade-offs between different technologies and to simultaneously evaluate pathways that consider all energy using sectors of the economy from a whole systems perspective. Typically, these models are employed in a deterministic fashion, producing a single pathway of the future evolution of the energy system for each set of input assumptions. This single pathway relies on a linear programing approach that optimises the total costs of the whole modelled system. Such an approach delivers solutions that are assumed to arise from the action of a benevolent social planning agent maximising the total welfare in the system [6o].

The global optimum solution is sometimes found at a very sharp peak or a deep trough in the multidimensional problem space and can be fragile when subjected to even small variations in input conditions [61]. It is sometimes argued that in the real world, under conditions of deep uncertainty, truly optimal solutions often do not exist [62]. A recent retrospective review of the UK electricity sector transition between 1990 and 2014 also found that a cost optimisation approach did not approximate realworld developments [63]. Estimates of the total system costs deviated by $9-23 \%$ and actual plant deployments were qualitatively very different between the modelled cost-optimal pathway and the real-world transition. These shortcomings point to the need for an expanded consideration of uncertainty in energy systems models [64].

Our approach, as demonstrated in this paper, is to combine the strengths of a whole system cost optimisation model with an advanced model for exploring patterns in uncertain futures. This approach analyses both strictly cost-optimised pathways as well as pathways that are "near-optimal". We employ a scenario-based approach to explore policy uncertainties that lead to changes in energy demand and GHG emissions [65]. To explore parameter uncertainty, we employ Monte Carlo simulation, where the input parameters are randomly sampled from user defined distributions of input variables [66]. Finally, to explore structural uncertainty we use 
the Modelling to Generate Alternatives (MGA) technique. MGA explores the space around a global optimum by allowing deviations from cost optimality, helping to address structural uncertainties that arise when the real-world transition deviates from the cost drivers [67-70].

This novel combined approach retains the strengths of a whole system energy economy model while offering new insights into the deep uncertainties surrounding the future evolution of the UK power sector, the decarbonisation of which is a key element in the energy and industrial strategy for the country [17-19]. While the UK context remains the focus of the paper, the insights are both novel and relevant for researchers and policymakers in other countries seeking to decarbonise their economies under the Paris Agreement.

\subsection{Method}

\subsection{Model background and key features}

In order to systematically explore a range of UK electricity sector transition pathways between 2010 and 2050, and appraise the associated investment costs in line with the study objectives outlined in Section 2.0, we employ a pair of energy system models, UKTM and D-EXPANSE. In this section, we first describe the background and key features of each of these models in turn, before illustrating their combined application.

\subsubsection{UKTM}

The UK TIMES Model (UKTM) [11], is a technology-rich partial equilibrium energy system optimisation model with perfect foresight, based on the International Energy Agency's Energy Technology Systems Analysis Programme (IEA-ETSAP) model generator $[71,72]$. UKTM was developed at the UCL Energy Institute as the successor to the UK-MARKAL model [73], which was used to underpin key decisions on UK energy policy from 2003-2013 [54]. The MARKAL and TIMES models have been used in the UK for much of the last decade to provide a whole systems perspective on decarbonisation pathways across the energy supply, industry, buildings, industry and transport sectors. As well as being used extensively for academic research $[11,14,74-$ 79], the models have played an important role in providing the evidence base for key energy strategy publications by the UK's Committee on Climate Change (CCC) and the UK Department of Energy and Climate Change (DECC) $[13,18,19,80,81]$ as well as supporting UK efforts under the United Nations Deep Decarbonization Pathways Project [82]. UKTM use continues in government under the recently formed UK Department for Business, Energy and Industrial Strategy (BEIS) following DECC's closure. Full documentation for UKTM can be found online [83].

According to the taxonomy of energy economic models by Hourcade et al. [84], UKTM is a bottom-up model that majors on technological detail rather than macroeconomic completeness. UKTM employs linear programming to make technology and fuel choices under greenhouse gas (GHG) emission and resource constraints. The model also includes other constraints, such as limits on technology build rates, and demand and supply matching in different diurnal and seasonal time periods to impart 
a degree of operational realism. A strength of UKTM for exploring energy transitions is that it captures the whole energy system and can account for cross-sector interactions, such as the allocation of scarce biomass resources between electricity generation, industry, transport, and heating [76]. In this study, UKTM is used to explore the energy economy wide picture and generate logically consistent whole system policy scenarios that provide boundary conditions for D-EXPANSE (discussed in more detail below in Section 5.2). These include pathway trajectories for future electricity demand and GHG emissions levels that are consistent with the UK energy system transforming to achieve different climate policy targets.

\subsubsection{D-EXPANSE}

Like UKTM, D-EXPANSE (Dynamic version of EXploration of PAtterns in Nearoptimal energy ScEnarios) is a technology-rich bottom-up optimisation model with perfect foresight. D-EXPANSE builds on past work using the EXPANSE methodology, described in [70]. As the model involves a set of highly computationally intensive techniques, D-EXPANSE focuses on representing the electricity sector only, rather than the whole energy system. D-EXPANSE can be distinguished from other optimisation tools through two key features that are not simultaneously combined in any other UK energy system models:

i. D-EXPANSE employs Monte Carlo simulation to take into account parametric uncertainty, e.g. exploring various assumptions for future technology costs, technology performance, or other key inputs.

ii. D-EXPANSE not only assesses cost-optimal pathways, but also uses a Modelling-to-Generate Alternatives approach [67-70] to explore the pathways that lie in the near-optimal region around the mathematically least-cost solution. As the diversity of such near-optimal solutions is vast, an algorithm to select a small number of maximally-different pathways is then used $[63,70]$. Such an approach allows D-EXPANSE to consider some structural uncertainties due to energy transition deviations from a pure cost rationale. In this study, a deviation of up to $15 \%$ in total system costs from the cost-optimal pathway is assumed; this is consistent with the past evidence [63].

D-EXPANSE significantly expands the consideration of uncertainty in energy system modelling due to the combination of Monte Carlo and Modelling-to-Generate Alternatives techniques. The model simultaneously generates and analyses a large ensemble of energy pathways (in this study, we explore 400 pathways for each DEXPANSE run: this is made up of 20 Monte Carlo runs with 20 cost-optimal and nearoptimal pathways for each). This allows for a systematic appraisal of investment costs associated with these multiple pathways. Full documentation for EXPANSE is provided in [63]. The model has also been tested in a multi-model comparison with other UK energy models [85]. 
Future energy system transitions are likely to involve a broad range of technologies and involve complex interactions between vectors such as electricity, heating, and transport. Analysis must therefore go beyond considering a single sector or a small range of technologies [86-88]. While the focus of the analysis in this paper, as outlined in the study objectives (Section 2.0), is resolving the myriad uncertainties facing future power sector investment, there is an obvious requirement to carry out this work within the context of a whole-system analysis of energy system decarbonisation. To achieve this, we combine for the first time the whole energy system model UKTM with the advanced exploratory pathway generator model DEXPANSE. The relationship between the two models is illustrated below in Figure 2.

Figure 2 - Analysis approach combining UKTM with D-EXPANSE

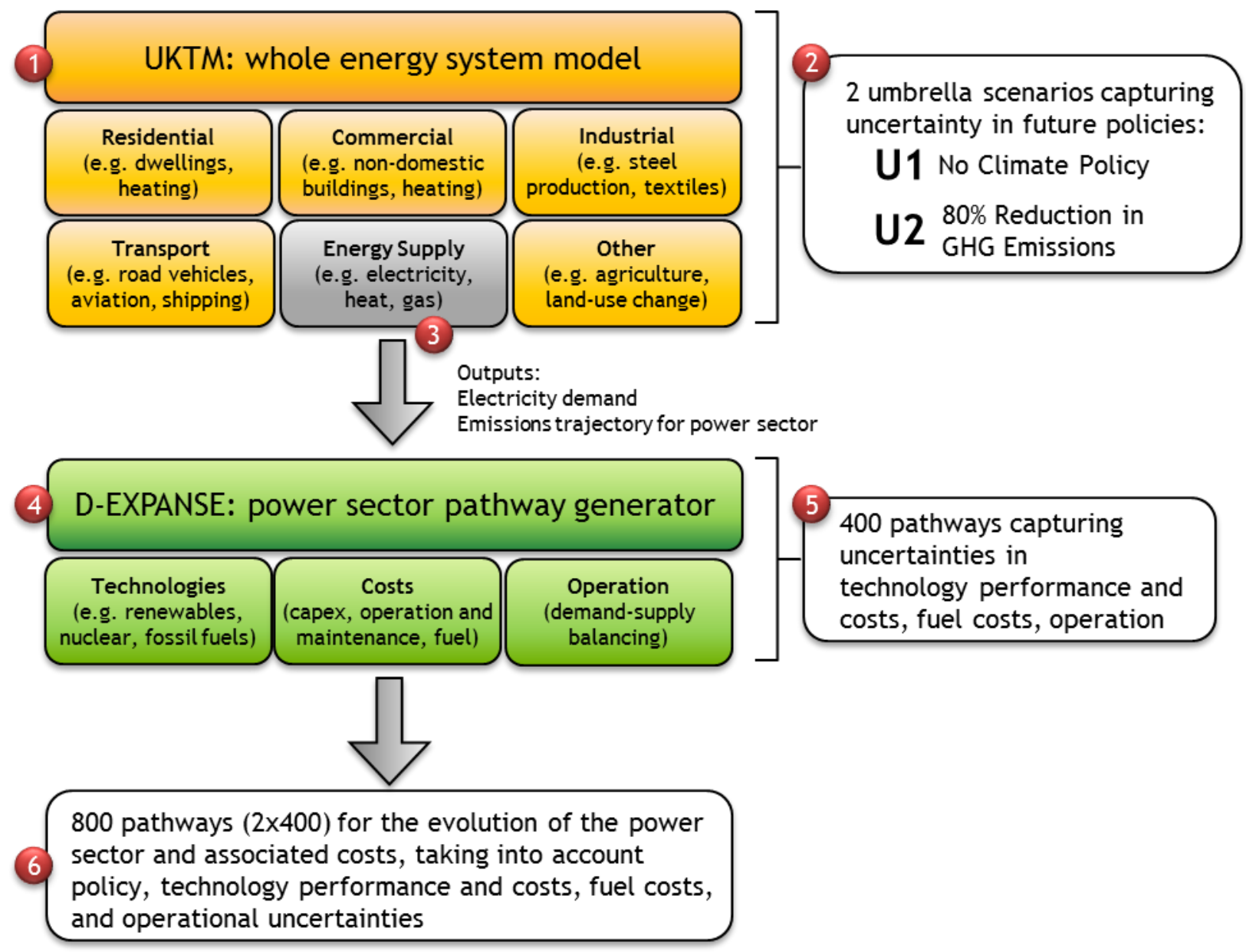

Figure 2 can be understood as a step-by-step process by following labels (1-6):

1) UKTM carries out a cost optimal evaluation of future changes to energy demand, GHG emissions, and technological diffusion in multiple sectors of the energy economy, including buildings, industry, transport, and energy supply.

2) UKTM is used to determine the energy economy-wide picture for future energy transitions over the period 2010-2050. Climate policy is a major 
driver of key system attributes such as technological change, total energy demand, and what fraction of key end-use sectors such as heating and transport become electrified. In this analysis we run UKTM twice to consider two different transitions. These represent two possible extremes for future national climate policy. We investigate:

- A No Climate Policy case (U1) where the energy system transition is guided by demand growth, technology availability and costs, being totally unconstrained by any policy requirement to reduce GHG emissions.

- An 80\% Reduction in GHG Emissions case (U2), where transitions must simultaneously meet growth in demand but also achieve UK national climate targets for 2050. This leads to strong increases in electricity demand due to heat and transport electrification as well as a technological shift towards low-carbon sources of electricity.

3) By taking into account the changes to energy demand and new technologies being deployed in other sectors in order to achieve the GHG targets specified by the policy conditions under (2), UKTM estimates the electricity demand and the emissions trajectory for the power sector under cost-optimal conditions. Electricity demand and power sector emissions over the period 2010-2050 are passed as constraints to D-EXPANSE.

4) D-EXPANSE is then used to explore a broad range of cost-optimal and near-optimal electricity generation pathways for the power sector that satisfy the electricity demand supplied by UKTM.

5) For each set of demand assumptions from UKTM, D-EXPANSE explores 400 separate pathways for the power sector, taking into account uncertainties in technology performance, technology costs, technology lifetimes, and plant operation (how much demand is met by each technology). No previous study simultaneous combines these elements.

6) The final set of results comprises 800 separate pathways for the evolution of the power sector.

\subsection{Modelling assumptions}

Both UKTM and D-EXPANSE consider energy transitions through time from 20102050 in 5-year intervals. Key model assumptions that affect fundamental considerations such as energy demand and GHG emissions are aligned with standard UK government assumptions used in decarbonisation pathway planning. These include an annual average GDP (gross domestic product) growth of $2.4 \%$ [89], and annual average population growth of $0.5 \%$ [90], which drives end-use demands in the UKTM model for energy services (heating, appliances, lighting, mobility, etc.). Industrial demand drivers are calibrated against outputs from the UK Department of Energy and Climate Change (DECC) as described in previous work using UKTM by Fais et al. [11]. 
The actual final demands for energy commodities such as electricity, heat and gas are computed endogenously by UKTM under the two umbrella scenarios $\mathbf{U}_{\mathbf{1}}$ and $\mathbf{U}_{\mathbf{1}}$, described above in Section 5.2, and are affected by considerations such as technological change and energy efficiency. This enables the model to use technological improvements to offset growth in demand if these choices are affordable and lie on the cost optimal pathway. Key results from UKTM are discussed later in Section 6.o.

In D-EXPANSE, carbon pricing under the 80\% Reduction in GHG Emissions scenario is based on guidelines for carbon valuation by DECC [91], while there is no carbon price signal applied in the No Climate Policy scenario. Fossil fuel prices are based on UK government projections [92], while the future costs and performance for energy generation technologies and their economic lifetimes are based on a series of reports commissioned by the UK government from major engineering consultancies [93-95]. The analysis explicitly takes into account future changes to costs and performance for different power sector technologies, such as reflecting the falling costs for renewable energy generation. Monte Carlo simulation is used in D-EXPANSE to explore how variation in these key uncertainties results in different power sector pathways.

A summary of key input parameters is given below in Table 2. Documentation for technology representation in IEA-ETSAP models can be found in work by Loulou et al. $[71,72]$. Detailed assumptions for the settings used in D-EXPANSE, including technological characterisation, are provided as Supplementary Material to the online version of this paper.

Table 2 - Key model input parameters for UKTM and D-EXPANSE

\begin{tabular}{|c|c|c|}
\hline Parameter & Source & Implementation \\
\hline Energy service demands & $\begin{array}{l}\text { Based on UK Department of } \\
\text { Energy and Climate Change } \\
\text { (DECC) [96], Office for } \\
\text { National Statistics [9o], } \\
\text { Office for Budget } \\
\text { Responsibility [89] }\end{array}$ & $\begin{array}{l}\text { Time series, } 2010-2050 \text {, in 5-year intervals; } \\
\text { Central drivers used for major end-use sectors (residential, } \\
\text { commercial, industrial, transport) in order to align with } \\
\text { standard UK government assumptions, including GDP } \\
\text { growth of } 2.4 \% \text { and population growth of } 0.5 \% \text { to } 2050 \text {. }\end{array}$ \\
\hline $\begin{array}{l}\text { Base year power generation } \\
\text { technology portfolio and existing } \\
\text { plant decommissioning profile }\end{array}$ & $\begin{array}{l}\text { Based on UK Department of } \\
\text { Energy and Climate Change } \\
\text { (DECC) [97] }\end{array}$ & UKTM and D-EXPANSE both calibrated to base year 2010. \\
\hline Fossil fuel prices and carbon pricing & $\begin{array}{l}\text { Based UK Department of } \\
\text { Energy and Climate Change } \\
\text { (DECC) [91] and [92] }\end{array}$ & $\begin{array}{l}\text { Time series, 2010-2050, in 5-year intervals; } \\
\text { Transposition to UKTM uses Central Projections; } \\
\text { Implementation in D-EXPANSE uses High, Central, Low } \\
\text { ranges as basis for distributions. }\end{array}$ \\
\hline $\begin{array}{l}\text { Power generation capital costs, } \\
\text { operation and maintenance costs, } \\
\text { and economic lifetimes }\end{array}$ & $\begin{array}{l}\text { Based on consultant reports } \\
\text { for the UK Department of } \\
\text { Energy and Climate Change } \\
\text { (DECC) by Parsons } \\
\text { Brinckerhoff }[93,94] \text { and } \\
\text { Arup }[95]\end{array}$ & $\begin{array}{l}\text { Time series 2010-2050, in 5-year intervals; } \\
\text { Implementation in D-EXPANSE uses High, Central, Low } \\
\text { ranges as basis for distributions; } \\
\text { So-called "First of a Kind (FOAK)" costs applied for fossil } \\
\text { thermal CCS and nuclear costs to 2024, with "Nth of a Kind } \\
\text { (NOAK)" costs, intended to reflect more mature technology } \\
\text { developments applied thereafter; } \\
\text { Real costs for key renewable energy resources such as } \\
\text { offshore wind and solar photovoltaics assumed to fall to } 2030\end{array}$ \\
\hline
\end{tabular}




\begin{tabular}{|c|c|c|}
\hline & & $\begin{array}{l}\text { and plateau thereafter in line with UK government } \\
\text { assumptions. }\end{array}$ \\
\hline Power sector capacity margin & \multicolumn{2}{|c|}{$\begin{array}{l}\text { Historically, the UK's Central Electricity Generating Board would have based system planning } \\
\text { requirements on a capacity margin of } 20 \% \text { during the period of public ownership of the } \\
\text { electricity system between } 1957-1990 \text { [98]. }\end{array}$} \\
\hline Power sector discount rate & UK Treasury [99] & $\begin{array}{l}\text { UK government guidelines for policy assessment are to use a } \\
\text { social discount rate of } 3.5 \% \text { to } 2040 \text { and } 3 \% \text { thereafter. }\end{array}$ \\
\hline $\begin{array}{l}\text { Demand and plant operation } \\
\text { assumptions }\end{array}$ & $\begin{array}{l}\text { As described in the UKTM } \\
\text { [83] and D-EXPANSE } \\
\text { documentations [63] }\end{array}$ & $\begin{array}{l}\text { UKTM features } 16 \text { different time-slices for supply-demand } \\
\text { balancing, and distinguishes between four diurnal time } \\
\text { periods (night, day, evening peak, late evening) and four } \\
\text { seasonal time periods (winter, spring, summer, autumn); } \\
\text { D-EXPANSE model supply-demand constraints for peak load, } \\
\text { shoulder load, and base load only. }\end{array}$ \\
\hline
\end{tabular}

\subsection{Results}

\subsection{System level energy and emissions trajectories}

Figure 3 shows the energy and emissions trajectories for the two umbrella scenarios used in this paper, $\mathbf{U}_{\mathbf{1}}$ and $\mathbf{U} \mathbf{2}$, and how they compare against 11 key low carbon scenarios from the UK literature on decarbonisation pathway analysis. These include 3 scenarios from the UK Energy Research Centre (UKERC) [100,101], 3 scenarios for the Committee on Climate Change (CCC) [102], 2 scenarios for the Department of Energy and Climate Change (DECC) [103], and 3 scenarios from the UK's Deep Decarbonization Pathways Project (DDPP) [82]. All scenarios (with the exception of U1, No Climate Policy) were carried out in the context of exploring UK pathways to achieving an $80 \%$ reduction in GHG emissions by 2050, compared to 1990 levels. Overall, Figure 3 shows that the $\mathbf{U}_{\mathbf{1}}$ and $\mathbf{U}_{\mathbf{2}}$ umbrella scenarios used in this study are fairly typical in energy consumption terms when compared to studies found in the literature, while the $\mathbf{U}_{\mathbf{2}}$ scenario also mirrors the steep decline in emissions found in past work.

Differences between the decarbonisation trajectories in the scenarios arise mainly from three sources: different treatment of non- $\mathrm{CO}_{2} \mathrm{GHGs}$ and international aviation and shipping, different base year conditions, and variation in the underlying demand, cost and performance data. The DDPP and $\mathbf{U}_{\mathbf{1}} / \mathbf{U}_{\mathbf{2}}$ scenarios both use the UKTM model which considers all GHG emissions, while the DECC, CCC and UKERC scenarios use the older UK-MARKAL model, which considered $\mathrm{CO}_{2}$ emissions only. A number of the scenarios using UK-MARKAL (i.e. some of the DECC, CCC, and UKERC scenarios in Figure 3) aimed for deeper cuts to $\mathrm{CO}_{2}$ emissions (e.g. a 90\% reduction target) to allow headroom for other non- $\mathrm{CO}_{2} \mathrm{GHGs}$, and to make allowances for emissions from the UK's share of international aviation and shipping. The scenarios using UKTM (U1, U2, and the DDPP scenarios) on the other hand consider all GHGs as well as international aviation and shipping endogenously. Other differences between results in Figure 3 occur from UK-MARKAL being calibrated to operate from 2000-2050, while UKTM is set to cover the period 2010-2050, and because models are frequently updated over time to reflect the latest demand, cost and technology performance 
data, as well as the latest climate science on issues such as land use change. These differences in the underlying data cause further variation between results.

Figure 3-Comparison of total energy and emissions trajectories

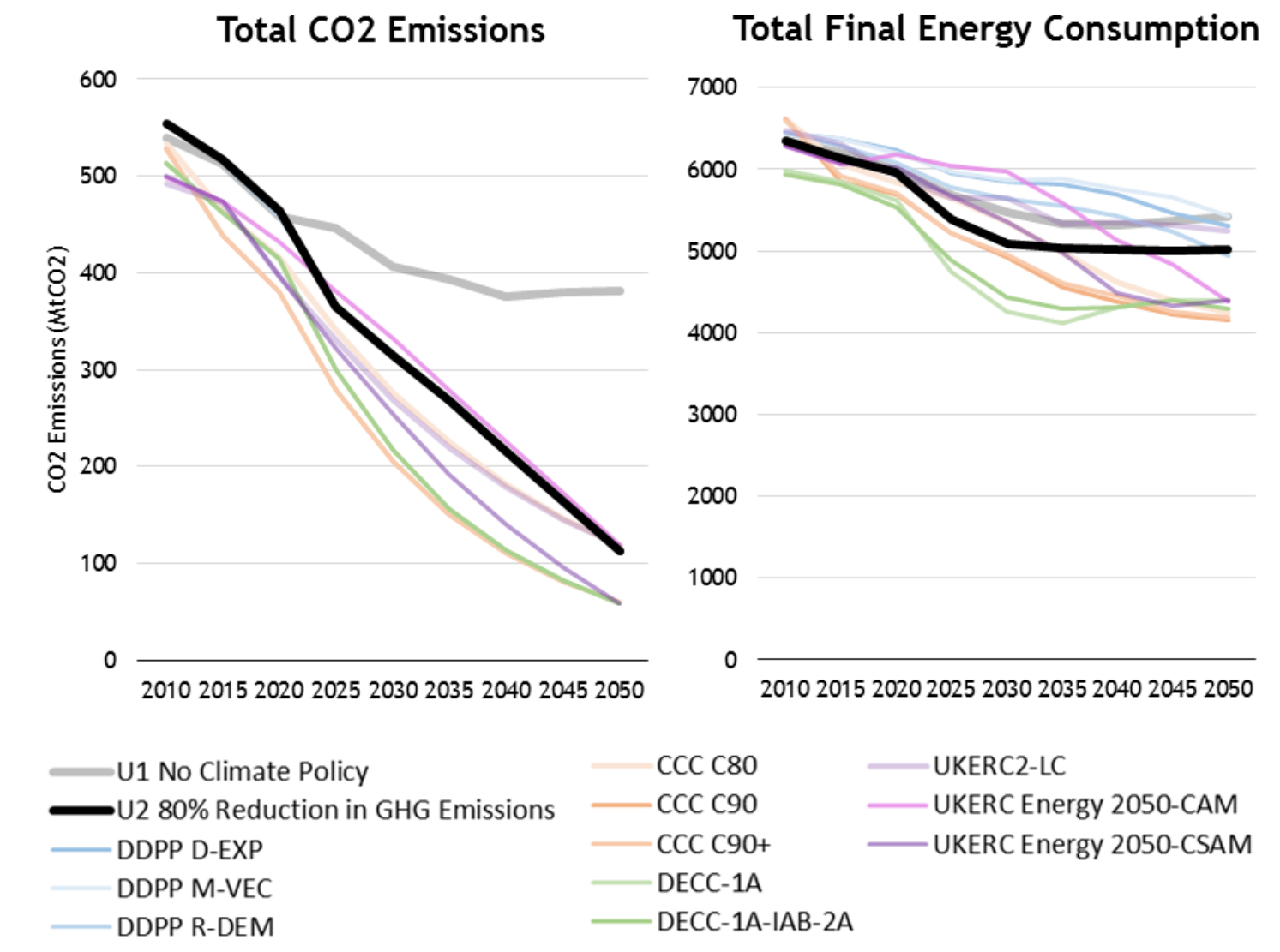

Figure 4 further disaggregates final energy consumption into key end-use sectors. As expected, the $\mathbf{U}_{\mathbf{1}}$ and $\mathbf{U}_{\mathbf{2}}$ scenarios show very similar trends to the DDPP model runs because they both use the UKTM model and the UK government's latest demand, cost, and technology data. They show higher residential energy consumption than many of the past studies using UK-MARKAL, but also show much lower industrial energy consumption. This possibly reflects the more detailed characterisation of the industrial sector and its technology options found in UKTM as compared to UKMARKAL, as well as the government's latest view on future industrial sector structure [11]. Future energy use in the commercial and transport sectors for $\mathbf{U}_{\mathbf{1}}$ and $\mathbf{U}_{\mathbf{2}}$ are within the ranges shown in past studies and are found to be most closely aligned with the DDPP and UKERC scenarios. 
Figure 4 - Comparison of final energy consumption by end-use sector

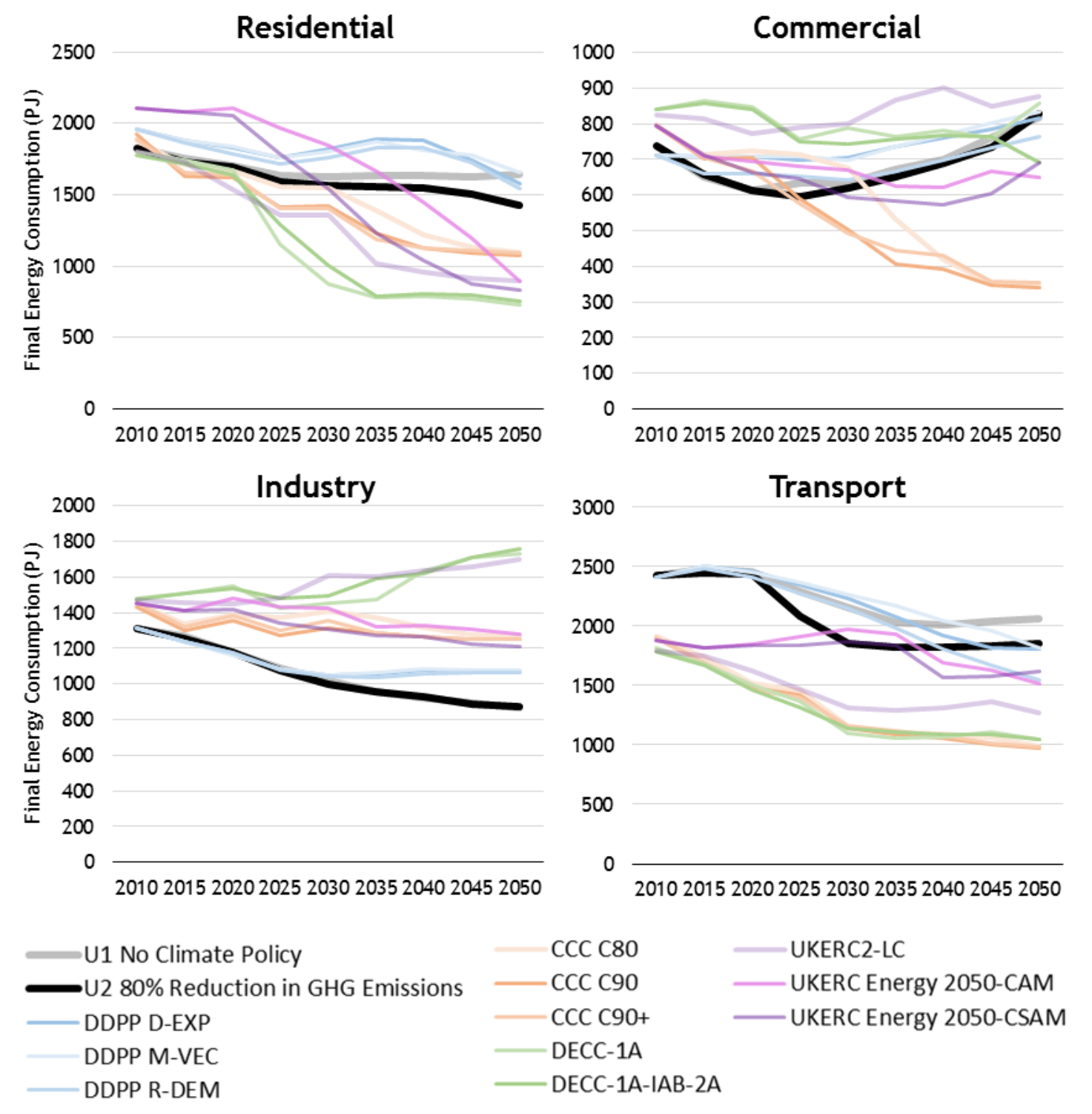

\subsection{Energy consumption and GHG emissions}

Figure 5 illustrates outputs from UKTM for final energy consumption (in petajoules, $\mathrm{PJ}$ ) and $\mathrm{GHG}$ emissions (in megatonnes of $\mathrm{CO}_{2}$ equivalent, $\mathrm{MtCO}_{2 \mathrm{eq}}$ ) across all modelled sectors and energy vectors. Three sets of data are visualised so that starting condition for the model in the 2010 base year can be compared against the final 2050 conditions from the two scenario pathways No Climate Policy, and 80\% Reduction in GHG Emissions. Figure 5 shows that both 2050 scenarios see absolute reductions in energy consumption when compared with the starting year of 2010 as more efficient technologies are deployed in spite of population growth and increased industrial and service sector demand.

In terms of GHG emissions, Figure 5 shows that these were $659 \mathrm{MtCO}_{2 \text { eq }}$ in the 2010 starting year. In the No Climate Policy scenario, some decarbonisation does occur in the period to 2050 as the relative costs of alternatives to fossil fuel technologies change across the time horizon. For example, low carbon energy supply costs fall and 
energy efficiency technologies become more widespread. These effects cause the No Climate Policy scenario to reduce GHG emissions to $474 \mathrm{MtCO}_{2 \text { eq }}$ by 2050.

In the $80 \%$ Reduction in GHG Emissions scenario, the uptake of low carbon technologies is significantly accelerated due to the binding emissions constraint used in the model i.e. the model must optimise technology selection to achieve the UK's 2050 target. Under these conditions, not only is there rapid uptake of energy efficiency options but negative emissions sequestration technologies such as bioenergy with CCS become economically attractive. Net emissions in 2050 are 228 $\mathrm{MtCO}_{2 e q}$, with significant emission reductions in buildings, industry and transport. This chart also shows that the power sector must become completely decarbonised in order for the energy system to achieve national targets.

Figure 5 - Total final energy consumption and emissions by sector

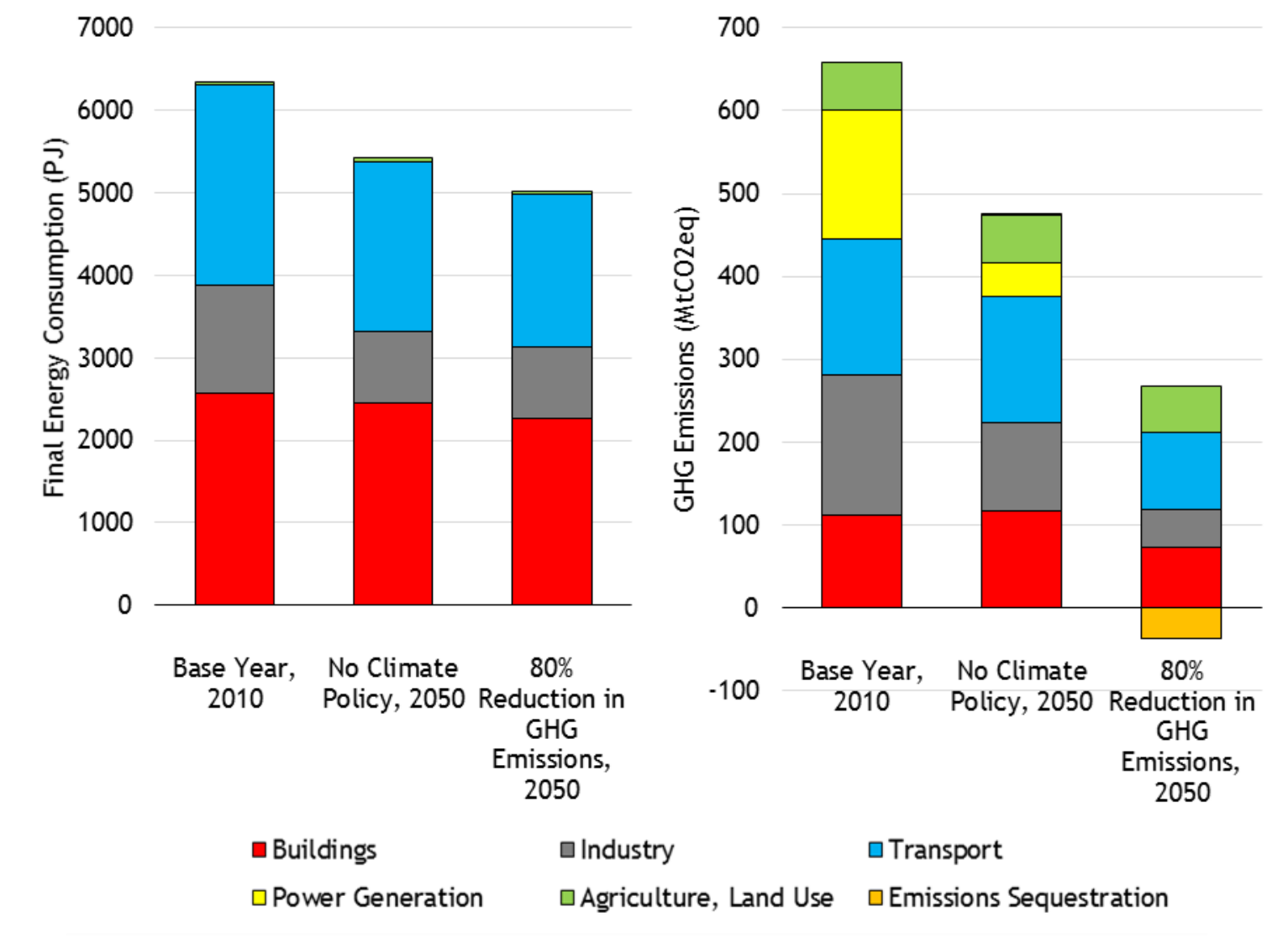

\subsection{Electricity consumption and electrification of end-use sectors}

Figure 6 illustrates key trends in electricity consumption that occur in the umbrella scenarios, focusing in particular on heating and transport. Total modelled consumption in 2010 is $1218 \mathrm{PJ}$ (338 TWh). Under the No Climate Policy scenario, electricity consumption falls in the period to 2050 by $30 \%$ to $852 \mathrm{PJ}$ (237 TWh), due to increased efficiency and shifts in industrial energy use. Under the $80 \%$ Reduction in GHG Emissions scenario, electricity consumption in 2050 remains at similar overall levels to 2010, standing at $1252 \mathrm{PJ}$ (348 TWh). The higher overall electricity use for the $80 \%$ Reduction in GHG Emissions scenario arises from an increased use of decarbonised electricity for heating and transport purposes as well as for industry, where there is a shift away from fossil fuel processes to more manufactured fuels such 
as hydrogen. The electrification of heating and transport is particularly pronounced in the $80 \%$ Reduction in GHG Emissions case, where it more than doubles from $196 \mathrm{PJ}$ (54 TWh) in 2010 to $470 \mathrm{PJ}$ (131 TWh) in 2050.

Figure 6 - Electricity consumption by end-use

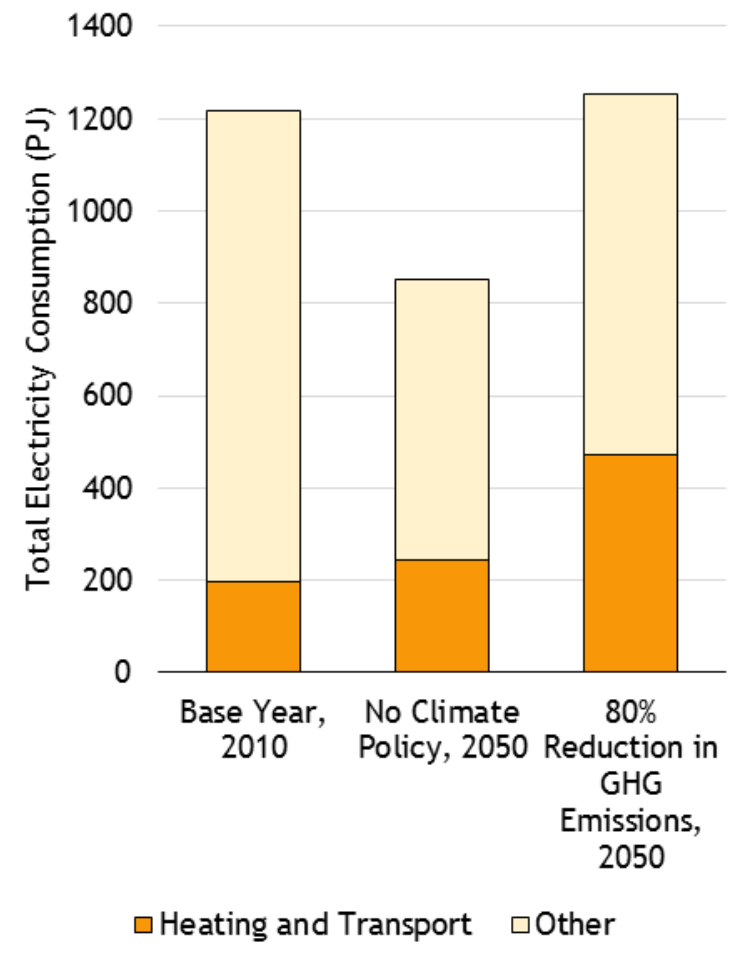

\subsection{Power sector technology pathways}

As described in Section 5.2, each of the two umbrella scenarios (U1, $\left.\mathbf{U}_{\mathbf{2}}\right)$ are implemented in D-EXPANSE with aforementioned inputs from UKTM. D-EXPANSE then generates an ensemble of pathways by combining Monte Carlo sampling and the MGA approach. For each umbrella scenario, 20 Monte Carlo runs are carried out. For every Monte Carlo run, one optimal pathway and 19 near-optimal pathways are generated. This gives an ensemble of 400 individual pathways for each of the two umbrella scenarios (80o in total). In each of the 800 pathways, the deployment of different technologies can vary significantly. In this section we illustrate the variation in deployment across all 800 pathways for different power generation technologies, including electricity from fossil fuels (with and without CCS), nuclear power, and renewable energy.

\subsubsection{Fossil fuel generation}

Figure 7 illustrates variation in fossil fired power plant deployment in umbrella scenarios U1 (No Climate Policy) and $\mathbf{U}_{\mathbf{2}}$ (80\% Reduction in GHG Emissions). Under conditions without emissions constraints (Figure 7a), it can be seen that there are many cost-optimal and near-optimal outcomes in which the deployment of coal power plants is significant. Coal power plant capacity in some pathways can be as high as $20 \mathrm{GW}$. If the UK achieves deep decarbonisation on the other hand (Figure $7 \mathrm{~b}$ ), the role of coal is shown to be significantly reduced, with deployment always below $5 \mathrm{GW}$ of capacity. This effect is also found to occur for thermal generation that 
includes a strong coal component, such as coal and biomass co-firing (Figure $7 \mathrm{c}$ and $7 \mathrm{~d}$ ). The loss of market share by coal-fired power plant in the low carbon scenario results in other technologies being deployed to fill the gap in supply requirements. This can be seen clearly in later sections.

The observations for natural gas fired generation are more nuanced. Low carbon policies appear to increase the deployment of open cycle gas turbines (OCGTs) while decreasing the potential for combined cycle gas turbines (CCGTs). OCGTs serve a core function in the UK power system by providing balancing services to the grid. Grid balancing is a requirement in both umbrella scenarios $\mathbf{U}_{\mathbf{1}}$ and $\mathbf{U}_{\mathbf{2}}$. OCGTs in this analysis show a similar total range of deployment between the maximum and minimum values in both umbrella scenarios. However, most of the modelled pathways under the No Climate Policy case (Figure 7e) feature a low installed base of OCGTs ( $<10 \mathrm{GW}$ ) when compared to the $80 \%$ Reduction in GHG Emissions case (Figure $7 f)$. Under the $80 \%$ Reduction in GHG Emissions scenario, there is a more uniform range of outcomes between the minima and maxima found for OCGT installed capacity (Figure $7 f$ ) i.e. more of the pathways rely on OCGTs for balancing (up to $\sim 20 \mathrm{GW}$ ). This indicates that more pathways in the climate constrained world show an increased requirement for peaking plants. This is correlated with increased use of renewable power (Section 6.4.4).

Combined cycle gas turbines (CCGTs), together with coal and nuclear plants, provide the UK's current baseload electricity generation. Under the No Climate Policy case (Figure 7g), there is less variation in CCGT deployment and most pathways only deploy up to $10 \mathrm{GW}$ of CCGTs because coal power, which is cost competitive with gas, remains an important player. Under the $80 \%$ Reduction in GHG Emissions case (Figure $7 \mathrm{~h})$, there is a much wider range of potential outcomes, including cases where up to $30 \mathrm{GW}$ of CCGTs are used. This wide variation in CCGT deployment in the nearoptimal pathways for the low GHG umbrella scenario can be attributed to both the constraints placed on coal due to its high per unit emissions on the one hand, and CCGT competition with other baseload technologies such as nuclear power and fossil fuel plants with CCS (see Sections 6.4.2 and 6.4.3) on the other. 
Figure 7 - Fossil fuel generation in cost-optimal and near-optimal pathways under umbrella scenarios $U_{1}$ and $U_{2}$

U1 No Climate Policy
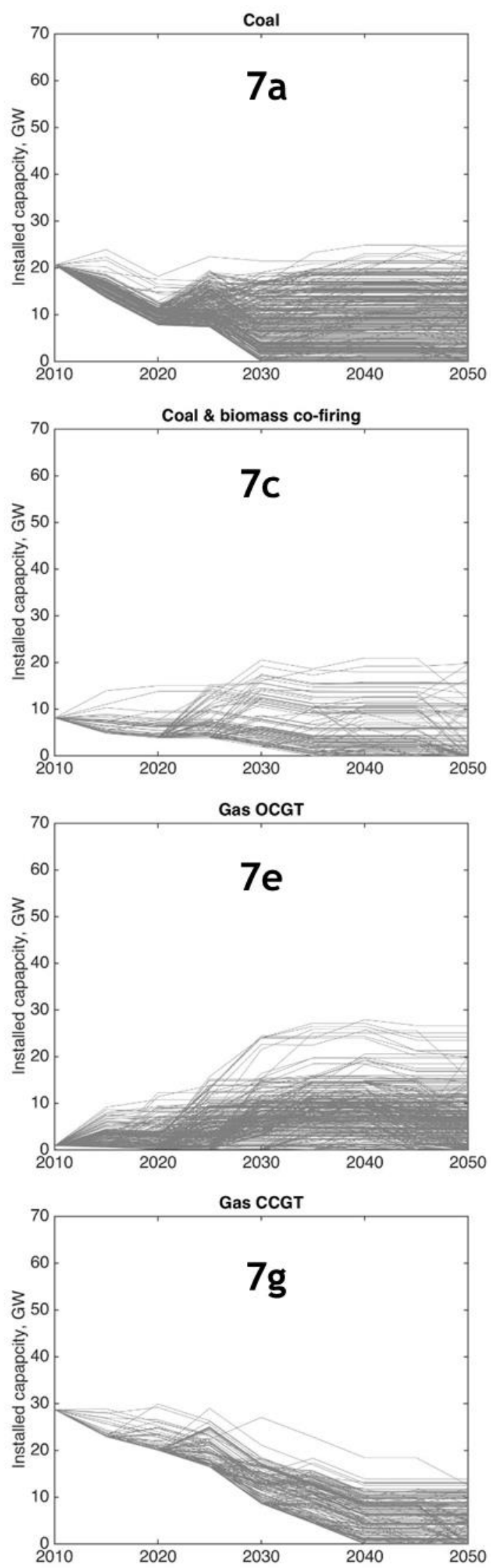

U2 80\% Reduction in GHG Emissions
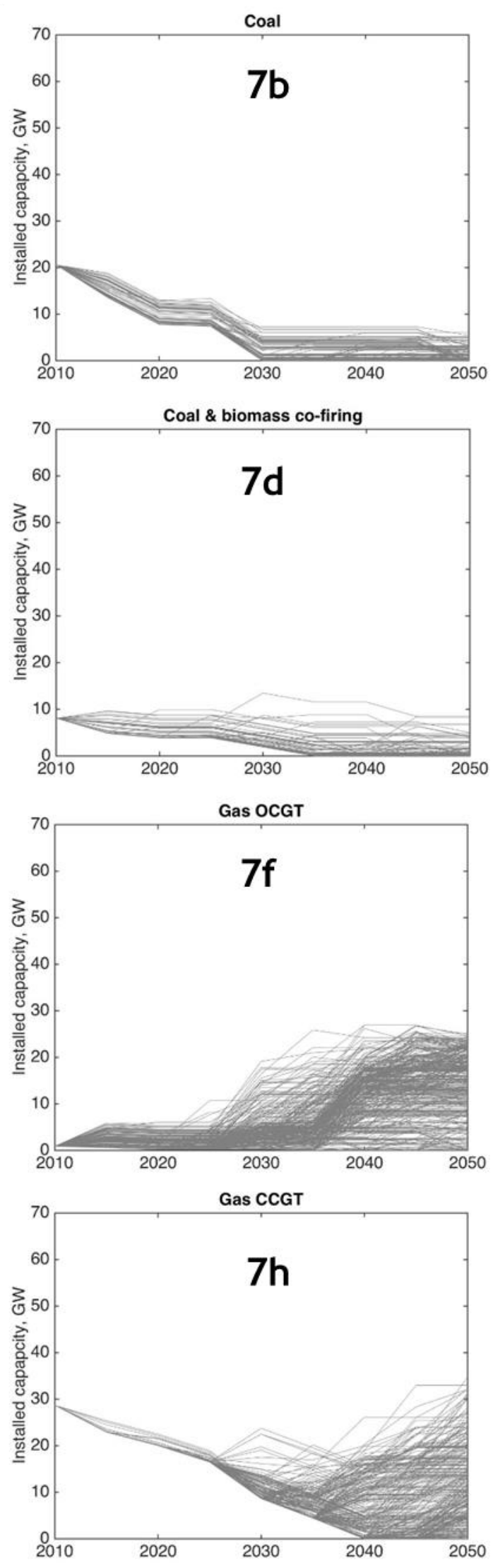


\subsubsection{Fossil fuel generation with CCS}

Figure 8 illustrates variation in the deployment of fossil fuelled power plants with CCS in the umbrella scenarios U1 (No Climate Policy) and U2 (80\% Reduction in GHG Emissions). With No Climate Policy, the installed capacity of both coal and gas CCS plant reaches almost 20GW (Figures $8 \mathrm{a}$ and $8 \mathrm{c}$ ), while under an $80 \%$ Reduction in GHG Emissions, it can be as high as $30 \mathrm{GW}$ (Figures $8 \mathrm{~b}$ and $8 \mathrm{~d}$ ). Implementing a binding national climate target therefore significantly increases the number of pathways that include fossil generation with CCS, which is intuitive as there exists a cap on GHG emissions released to atmosphere.

However, the range of installed capacity outcomes under umbrella scenario $\mathbf{U}_{\mathbf{2}}$, both for coal CCS and gas CCS, is large and some pathways include little or no CCS plant. This broad range of possible outcomes reflects the fact that these technologies are broadly interchangeable with one other (in cost and performance terms) as well as with other forms of low carbon generation, such as natural gas (Section 6.4.1), nuclear power (Section 6.4.3) or renewables (Section 6.4.4). The closer that the total costs of these technologies are to one another, the greater the degree of interchangeability observed in the near-optimal space.

Figure 8 - Fossil fuelled plants with CCS in cost-optimal and near-optimal pathways under umbrella scenarios $\mathrm{U}_{1}$ and $\mathrm{U}_{2}$

U1 No Climate Policy
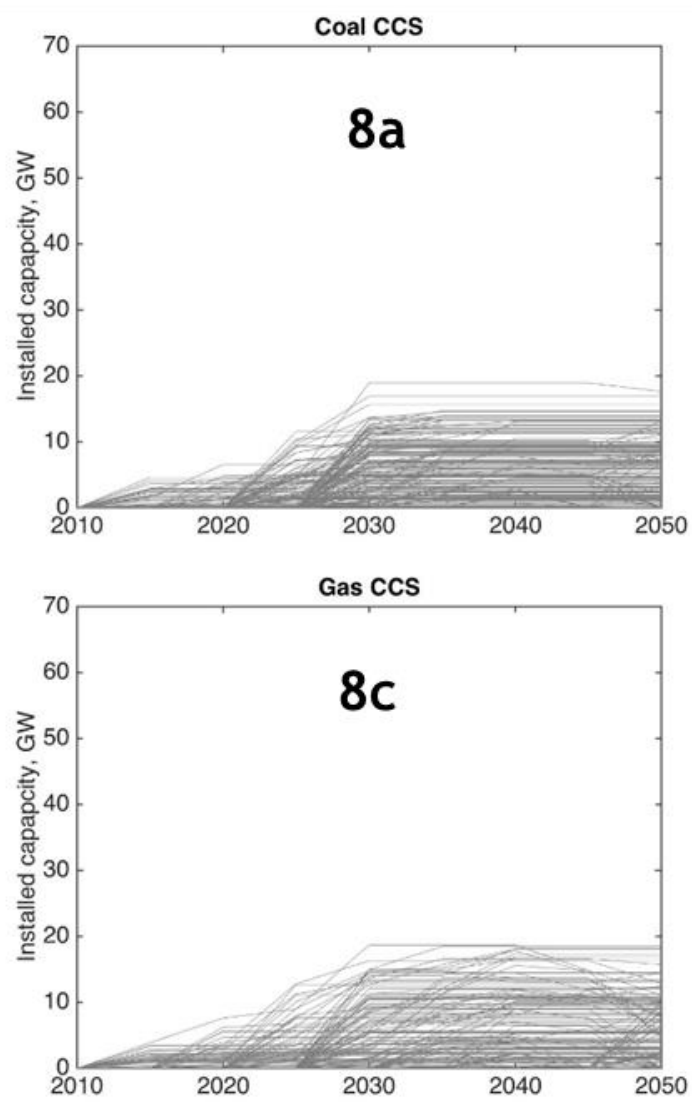

U2 $80 \%$ Reduction in GHG Emissions
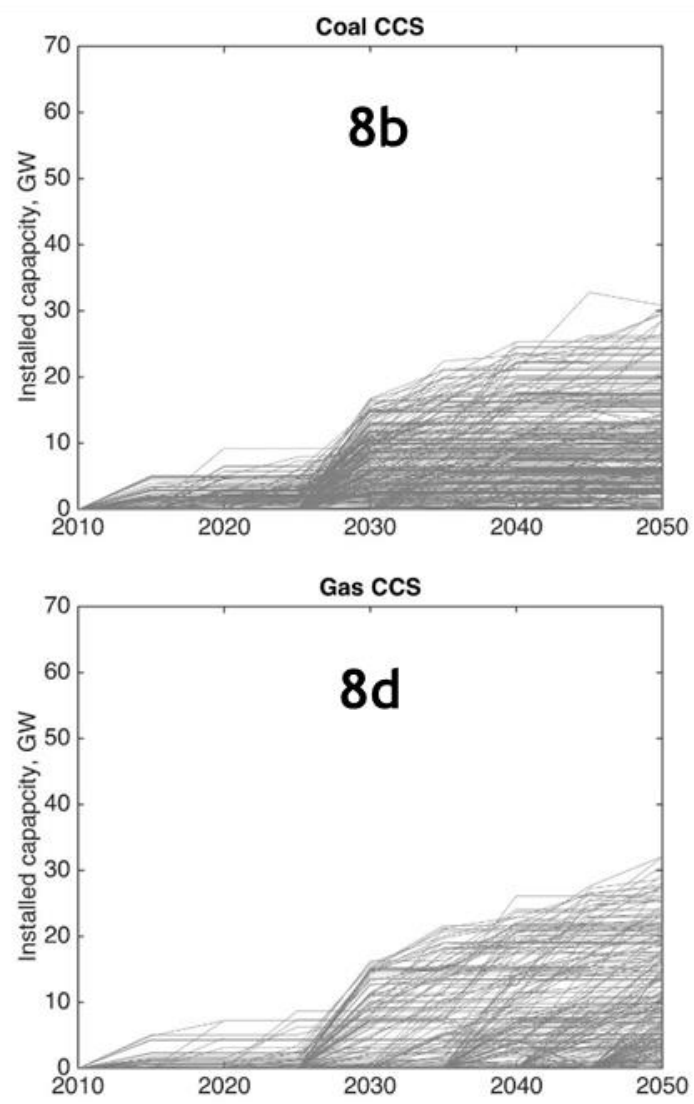


\subsubsection{Nuclear power}

Figure 9 illustrates variation in nuclear power deployment between scenarios $\mathbf{U}_{\mathbf{1}}$ and U2. There is a broad range of outcomes for all pathways, which reflects the competition faced by nuclear power from other centralised power generation technologies such as coal and gas CCS. The maximum potential for nuclear power found under the pathways explored with No Climate Policy (Figure ga) is found to be around $20 \mathrm{GW}$, while under an $80 \%$ Reduction in GHG Emissions (Figure $9 \mathrm{~b}$ ) it is as high as $32 \mathrm{GW}$. This reflects an increased demand for low carbon sources of baseload electricity generation in pathways that include for climate policy considerations and a loss of market share for unabated coal and gas generation (Sections 6.4.1 and 6.4.2).

Figure 9 - Nuclear power in in cost-optimal and near-optimal pathways under umbrella scenarios $U_{1}$ and $U_{2}$

U1 No Climate Policy

U2 $80 \%$ Reduction in GHG Emissions
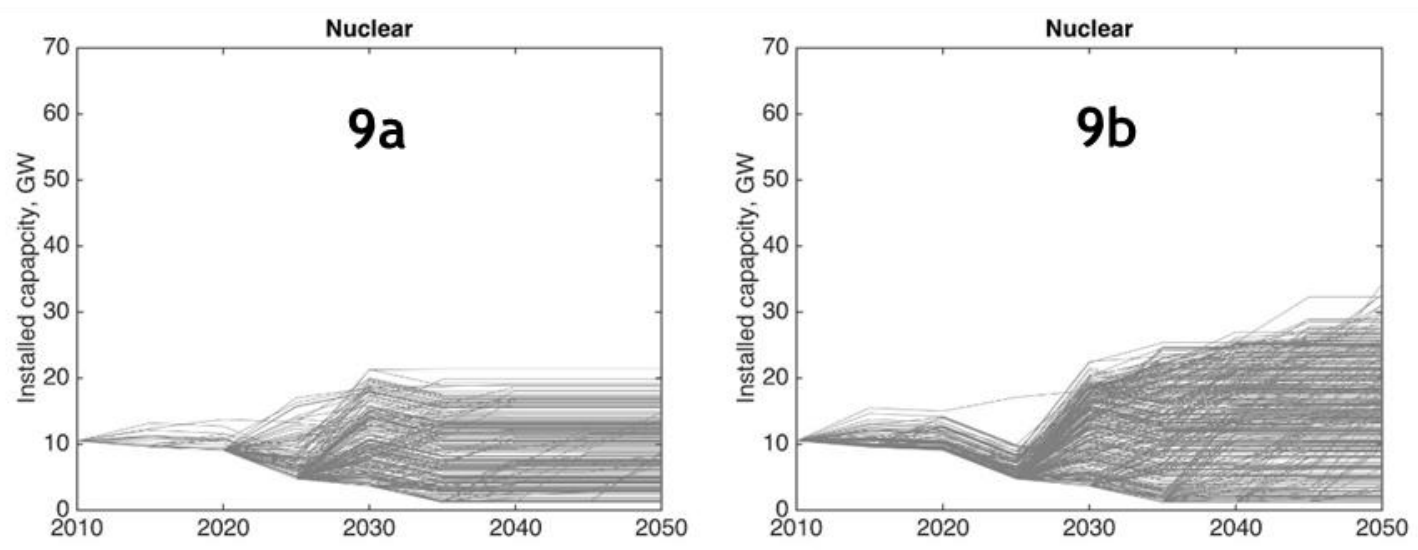

\subsubsection{Renewable technologies}

Figure 10 illustrates variation in the deployment of wind and solar power and Figure 11 shows the deployment of marine and biomass technologies. The D-EXPANSE model also considers hydropower, biogas, and electricity generation from waste, but they are not illustrated here due to their relatively minor role in the overall modelled UK electricity mix. It can be seen from Figure 10 that a significant deployment of renewable technologies is possible by 2050 in pathways modelled under both the No

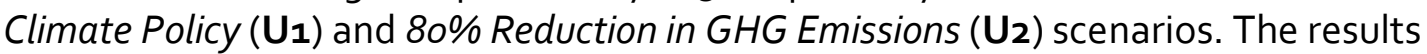
show that a greater number of pathways tend to make use of onshore and offshore wind resources when the model is run with a climate target (see Figures 1ob and 1od).

Deployments of solar PV capacity of up to $20 \mathrm{GW}$ by 2050 are found in both the $\mathrm{U}_{\mathbf{1}}$ and $U_{\mathbf{2}}$ cases (see Figures $10 e$ and $10 f$ ). Interestingly the pathway assessment finds that the deployment of solar PV is lower after 2035 in the climate-constrained world of $U_{\mathbf{2}}$ than in the unconstrained $U_{\mathbf{1}}$ scenario. This result stems from the fact that under the U2 scenario a large stock of low-carbon technologies must already installed by the year 2030 in order to replace decommissioned fossil fuel-based generation that reaches the end of its lifecycle in the 2020's. Solar PV, which has comparable costs to other low-carbon technologies by 2030, does see deployment in most pathways during this period, but begins to face increased competition from wind, nuclear and 
CCS after 2030. These technologies push the total system costs up, crowding out additional deployment of solar PV, whose low capacity factor still results in relatively high overall costs despite technology learning effects bringing down its capital costs. Solar PV also contributes relatively little to capacity required for meeting peak electricity demand and is thus outperformed by other low-carbon technologies. In the U1 case the total system costs are lower due to the significant capacity of cheaper coal and gas generation. Near-optimal U1 pathways can thus accommodate costlier solar PV without raising the total system costs beyond the near-optimal threshold. An expanded discussion of our observations on investment costs can be found in Sections 6.6 and 6.7.

Figure 10 - Wind and solar power plants in cost-optimal and near-optimal pathways under umbrella scenarios $\mathrm{U}_{1}$ and $\mathrm{U}_{2}$

U1 No Climate Policy
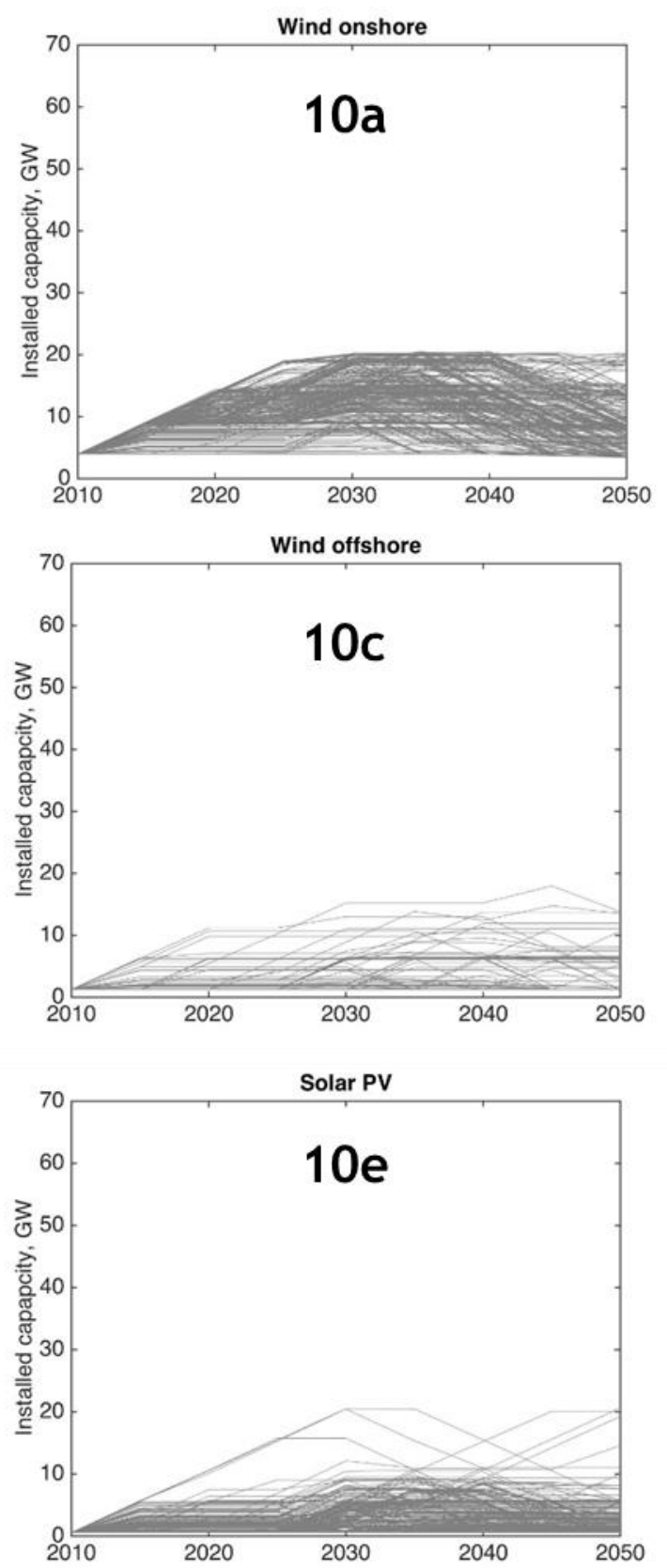

U2 80\% Reduction in GHG Emissions
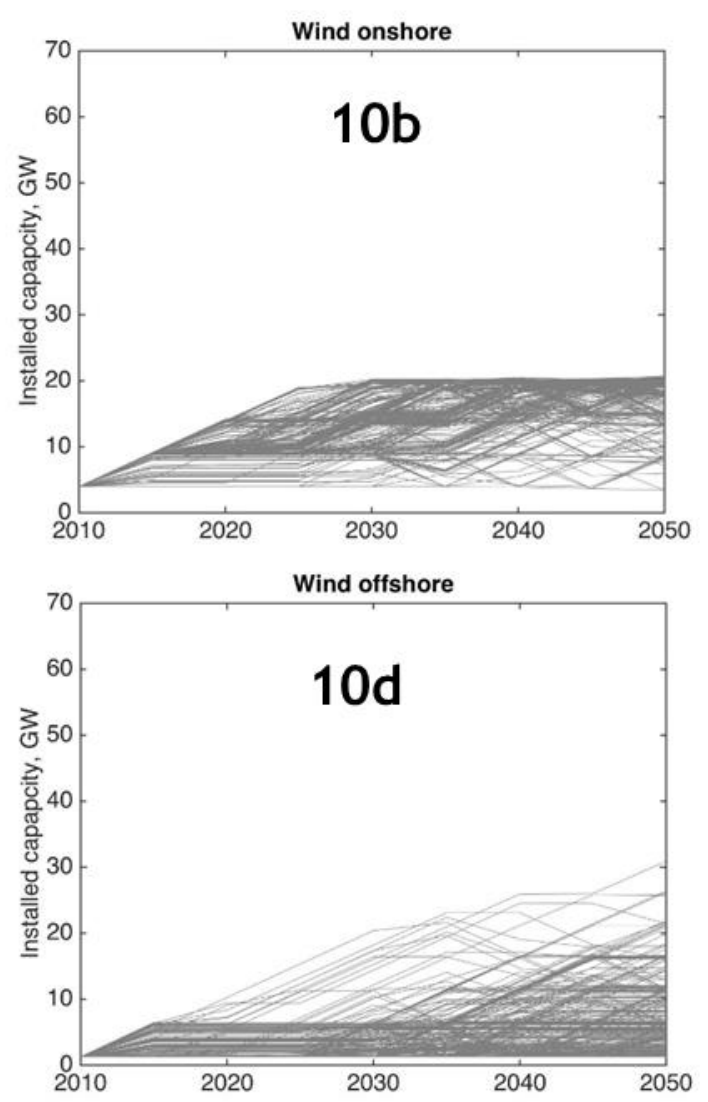

Solar PV

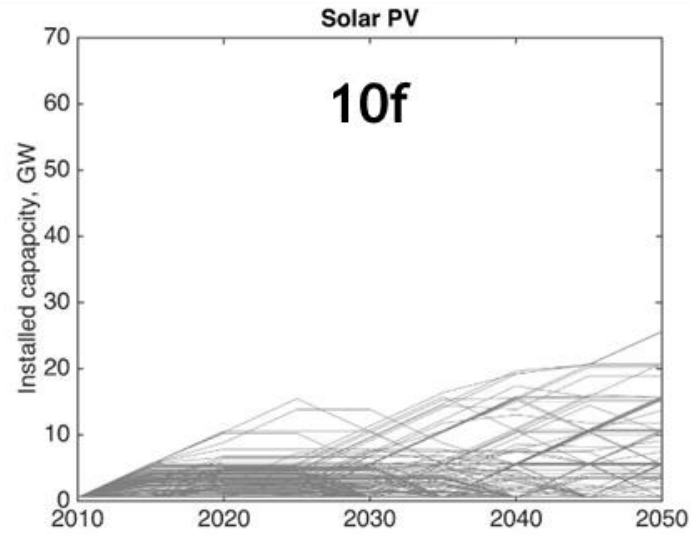


Figure 11 shows that marine and biomass power see limited deployment across all pathways, due to restricted resource availability. There is however, an increased density of pathways above the zero line for all technologies under the low GHG umbrella scenario $U_{2}$ (Figures 11 b, 11d, and $11 f$ ). As with other pathways explored under the $80 \%$ Reduction in GHG Emissions scenario, this reflects an increased demand for low-carbon power and the displacement of unabated coal and natural gas plant.

Figure 11 - Marine and biomass power plants in cost-optimal and nearoptimal pathways under umbrella scenarios $U_{1}$ and $U_{2}$

U1 No Climate Policy
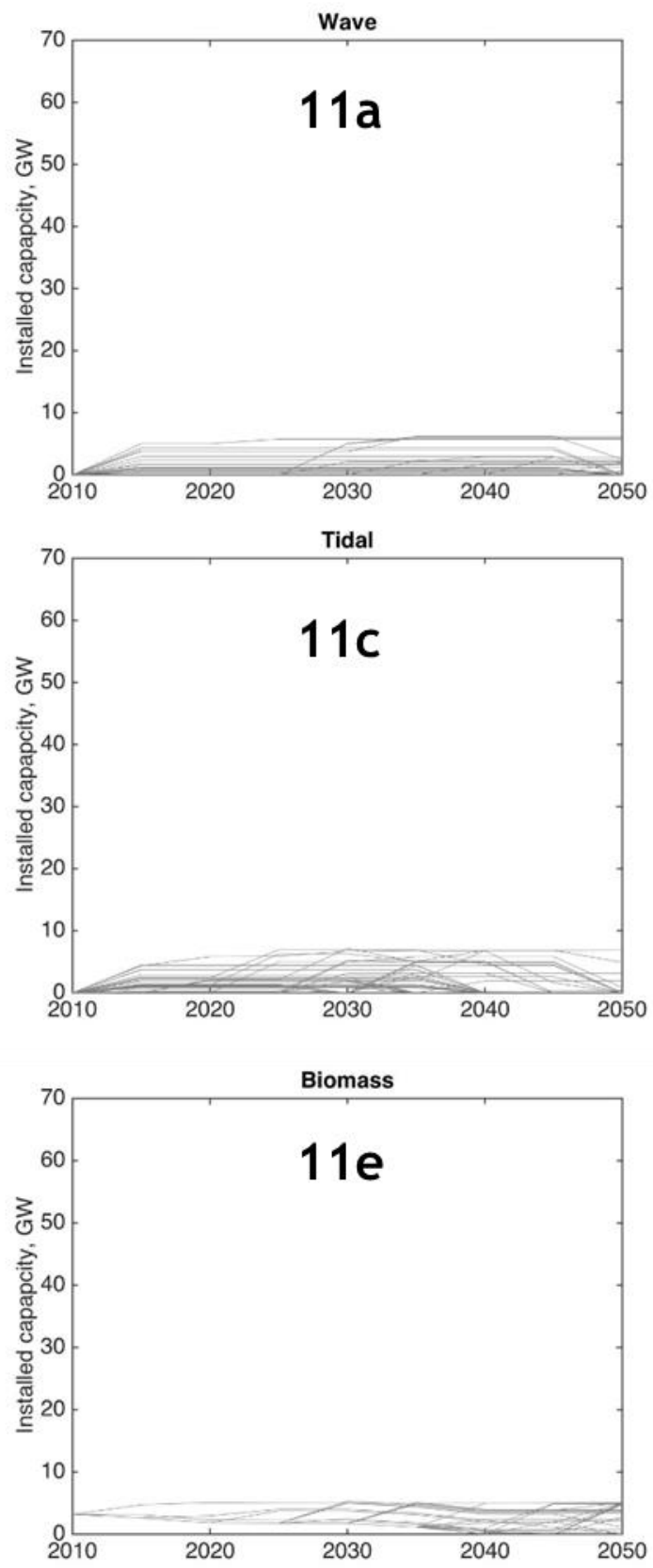

U2 $80 \%$ Reduction in GHG Emissions
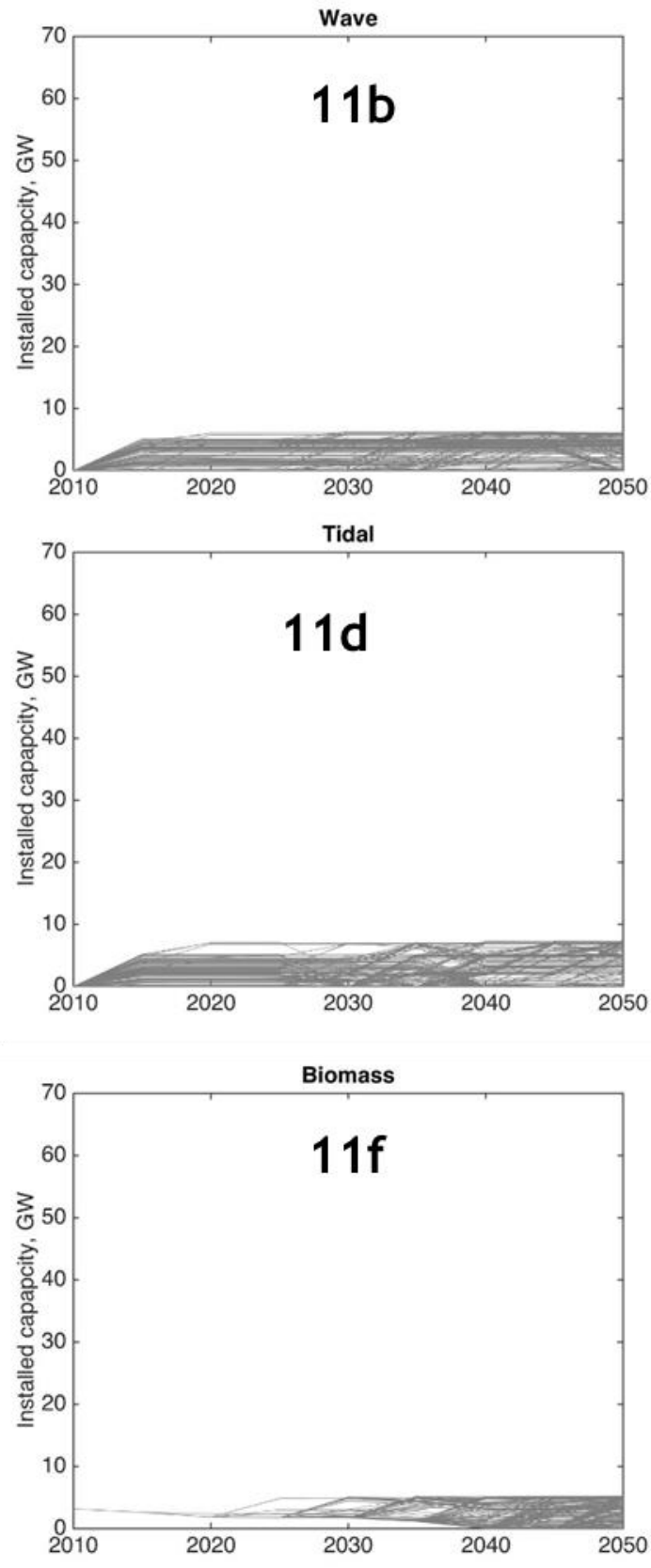


\subsection{Maximally-different pathways}

Section 6.4 discussed the variation in deployment levels for individual technologies under cost-optimal and near-optimal pathways, but did not illustrate how these technologies combine into complete transition pathways. A key feature of DEXPANSE is the identification of pathways within the near-optimal space that are "maximally different" from one another. By "maximally different", we mean that these scenarios are a subset of the total ensemble of simulated pathways that differ from each other as widely as possible. This is determined using an adapted distanceto-selected algorithm using harmonic averages [104], as described in previous work using the EXPANSE methodology [70].

Figure 12 illustrates nine maximally-different pathways from the 400 pathways generated for umbrella scenario U2. All of the pathways start with the same power sector technology portfolio in 2010, but ultimately arrive at very different places by the year 2050. For example, some pathways show a transition towards a future characterised primarily by large centrally dispatched technologies such as CCGTs coal and gas CCS, and nuclear power (Figures 12a, 12e, 12f, 12h), while other pathways demonstrate combinations of central generation with wind and solar power (Figures $12 \mathrm{~b}, 12 \mathrm{c}, 12 \mathrm{~g}$ ). Finally, there are examples of highly diverse pathways that include roles for nearly all modelled technologies (Figures 12d, 12i). 
Figure 12 - Examples of nine maximally-different pathways in umbrella scenario $U_{2}$
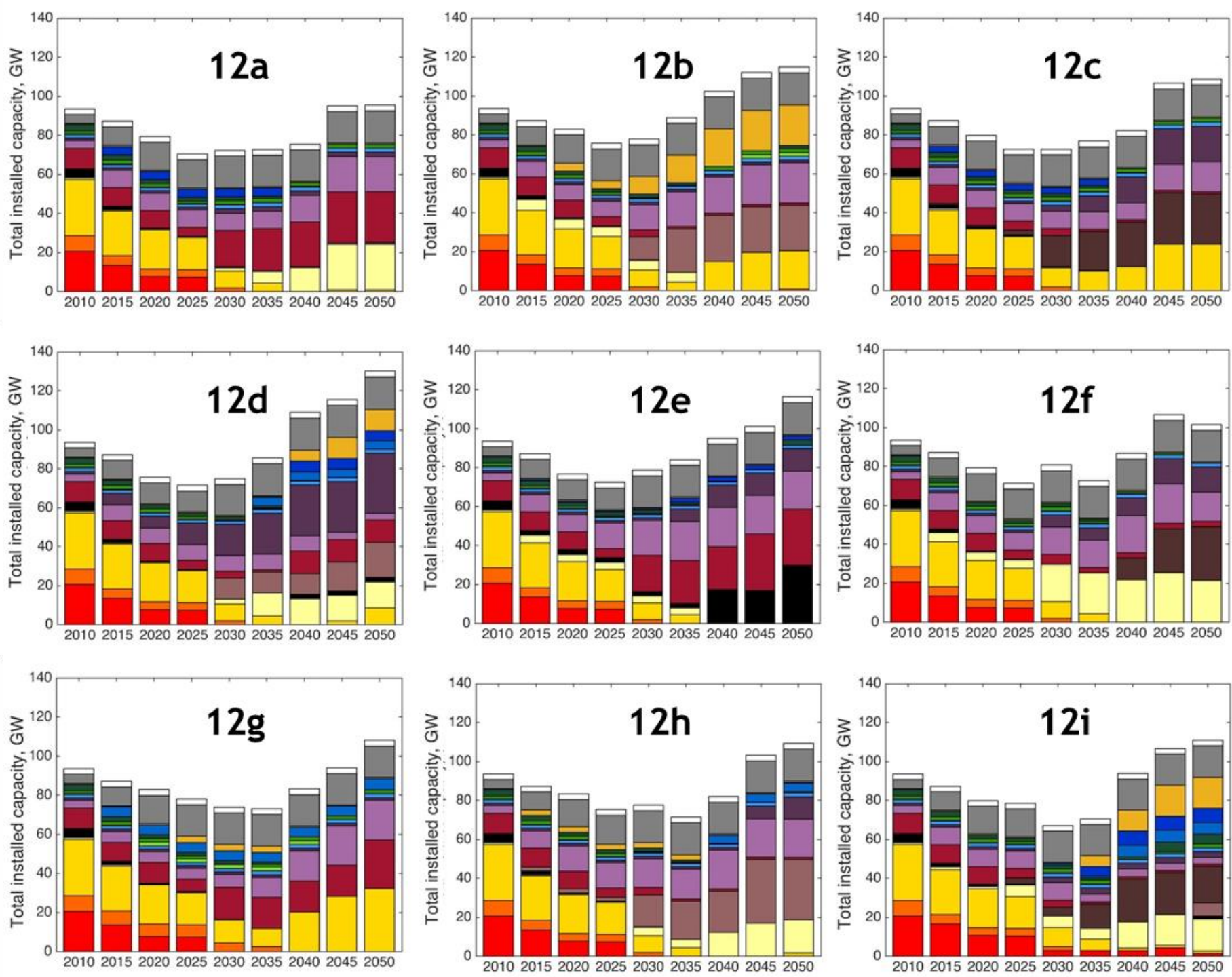

\begin{tabular}{|l|l|}
\hline Pumped storage & Waste \\
Interconnectors & Hydro \\
\hline Solar PV & Wind offshore \\
\hline Tidal & Wind onshore \\
\hline Wave & Nuclear \\
\hline Biomass & Gas CCS \\
\hline Biogas & Coal CCS \\
\hline Bar
\end{tabular}

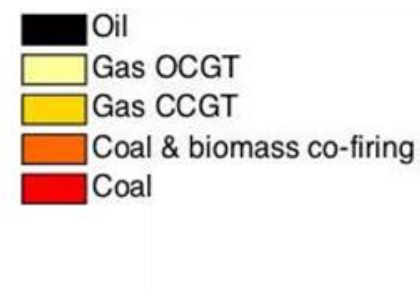


While Figure 12 shows a number of example transitions through time, Figure 13 focuses on the maximally-different power sector portfolios for the target year of 2050, comparing the results from the No Climate Policy (U1) umbrella scenario against those that achieve an $80 \%$ Reduction in GHG Emissions (U2). The installed capacity for power generation in the No Climate Policy Case is generally found in the region of 60 $-77 \mathrm{GW}$, while under an $80 \%$ Reduction in GHG Emissions it is much higher, being between $100 \mathrm{GW}$ and $130 \mathrm{GW}$. The large difference arises from fundamental differences in electricity demand between the two umbrella scenarios. The whole energy system model runs carried out under UKTM show that to meet climate targets under umbrella scenario $\mathbf{U}_{\mathbf{2}}$ there is a significant increase in electricity consumption associated with electrification of end-use demands such as building heating and transport (Sections 6.2 and 6.3). Another factor contributing to higher installed capacities under umbrella scenario $\mathbf{U}_{\mathbf{2}}$, is that many of the sources of low-carbon energy that are deployed are intermittent in nature, and require additional supporting generation plant to cover periods when they do not operate.

Many observations regarding technological variation, previously discussed in Section 6.4, can also be recognised in this diagram. For example, there are more pathways with a high deployment of CCGTs under the climate constrained scenario (U2), and much fewer employing unabated coal fired power plants. Overall there is a high diversity of pathways that fall within the cost-optimal and the near-optimal range, a finding that is consistent with previous MGA exercises $[63,68]$. This diversity reveals the multiplicity of future options for decarbonising the UK power sector that could evolve under future government policy choices, governance arrangements, and market developments.

Figure 13 - Maximally-different pathways in 2050 for umbrella scenarios $U_{1}$ and $U_{2}$

U1 No Climate Policy U2 $80 \%$ Reduction in GHG Emissions
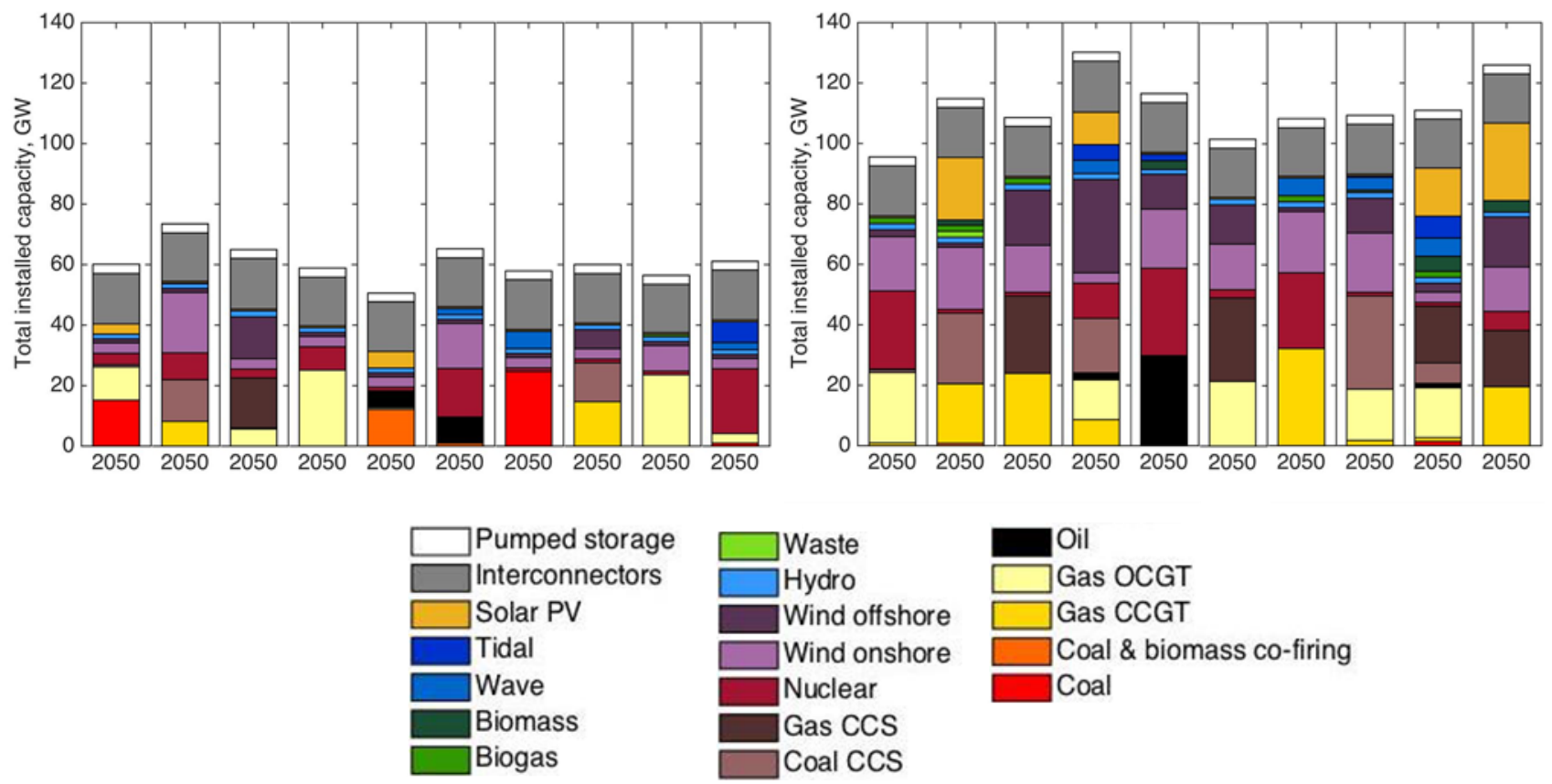

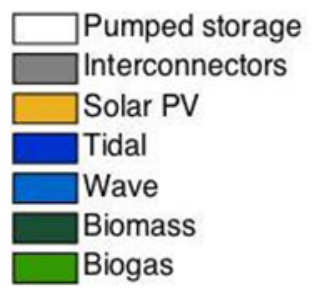

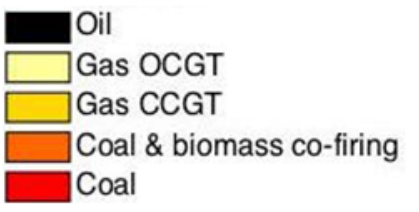




\subsection{Cumulative investment costs}

Rather than present an investment appraisal for each and every single one of the 400 pathways assessed for each of the two umbrella scenario (U1 and $\mathbf{U}_{\mathbf{2}}$ ), we instead compare distributions of results to understand the broad patterns or trends that emerge from the analysis. Figure 14 compares the temporal distribution of cumulative total investment costs into UK electricity generation as a whole. Boxplots are used to illustrate the mean, the interquartile range (between the $25^{\text {th }}$ and $75^{\text {th }}$ percentile), and the maximum and minimum estimates for all pathways. It can be seen immediately in Figure 14 that the tails of the investment cost distributions are very long. This is to be expected, as a broad range of uncertainties, including technology characteristics, costs, climate policy considerations and the final demand for electricity are accounted for. Figure 14 also shows that the level of uncertainty in the cost estimates for all pathways increases through time.

Considering both the maxima and minima across all cost pathways, Figure 14 shows that under the No Climate Policy scenario, cumulative investment costs range from f45 bn to $f 110 \mathrm{bn}$, while under an $80 \%$ Reduction in GHG Emissions, they are between $£ 75$ and 21obn. If the more extreme outliers are not considered and we focus on the interquartile ranges, we find that cumulative investment costs for the No Climate Policy scenario are between $£ 6$ obn and $£ 75 \mathrm{bn}$, while under an $80 \%$ Reduction in GHG Emissions they are between $£ 110$ and $£ 140 \mathrm{bn}$. In general terms therefore, it can be seen that achieving UK policy targets for 2050 approximately doubles the investment required in the power sector under most of the possible technology pathways. This finding is consistent with observations made in Section 6.3, which show that achieving climate targets may require large increases in installed capacity owing to the electrification of significant end-use sectors such as transport and heating. Not only is there an increase in capacity, but there is also a shift towards low carbon generation, which also increases costs further. This is because many low-carbon technologies are capital-intensive, and replace fossil fuel based plants that have high operational rather than investment costs. Another contributing factor is the intermittent nature of many sources of low carbon electricity, which leads to additional investment in supporting generation capacity. 
Figure 14 - Comparison of cumulative investment costs for umbrella scenarios $U_{1}$ and $U_{2}$. The boxplots depict mean, $25^{\text {th }}$ and $75^{\text {th }}$ percentiles, upper and lower bound of cumulative investments costs.

U1 No Climate Policy

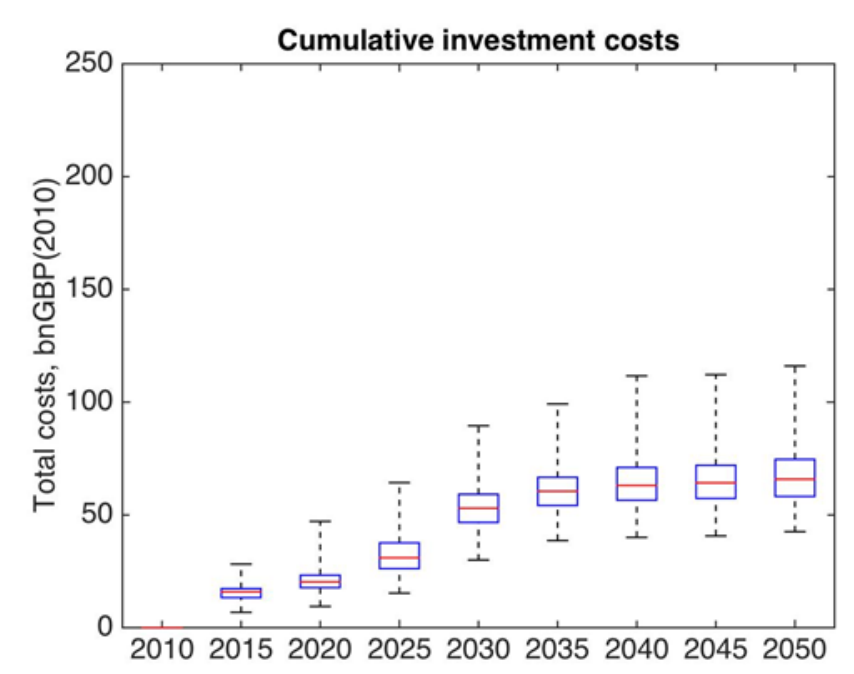

U2 $80 \%$ Reduction in GHG Emissions

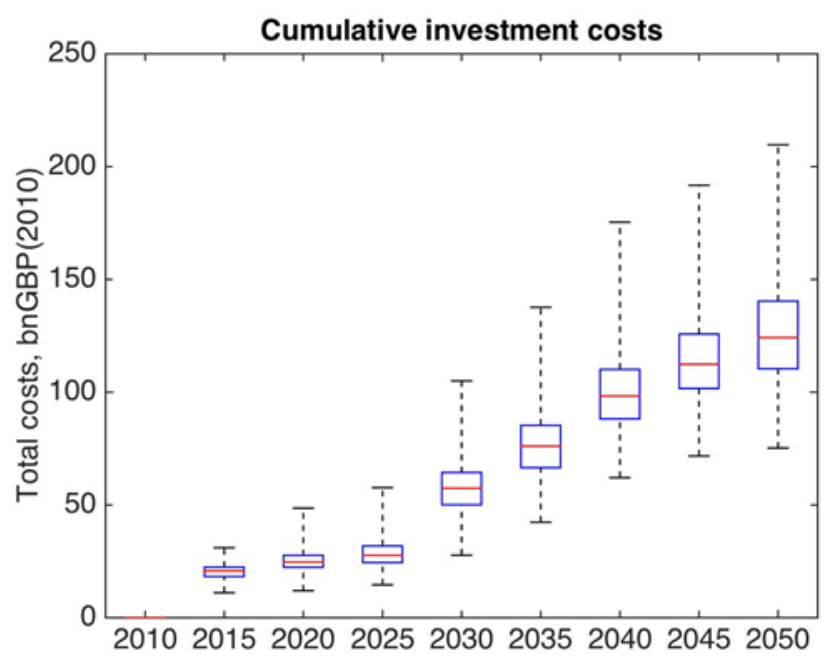

\subsection{Annual investment costs}

Figure 15 illustrates variation in annual investment costs for each umbrella scenario. As with Figure 14, the tails of the distributions in Figure 15 are again very long due to the vast diversity of plausible pathways found in the near-optimal space. Figure 15 shows that there is a range of investment patterns through the time horizon, and that there are instances of pathways with very low annual investment in one time segment followed by very high annual investment in the next segment, and vice versa. Looking at the interquartile ranges and comparing between the two umbrella scenarios ( $\mathbf{U}_{\mathbf{1}}$, $U_{2}$ ), it can be seen that most pathways have distinct peaks in investment levels at similar time periods. The first peak in investments for most pathways occurs after 5 years of model time, in 2015, and is associated with the retirement of existing UK fossil fuelled generation capacity (much of which is due to be decommissioned before 2020). The second peak occurs 15 years into the time horizon in 2030. It can also be seen that the pattern of investment in the period 2035-2050 is different in both cases. We can compare these three distinctive periods as follows:

- 2015 investment peak: under the No Climate Policy scenario, the interquartile range is between $£ 2.5 \mathrm{bn} / \mathrm{year}$ and $£ 3.5 \mathrm{bn} / \mathrm{year}$, while under an $80 \%$ Reduction in GHG Emissions it is slightly higher and between

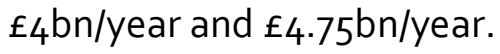

- 2030 investment peak: under the No Climate Policy scenario, the interquartile range is between $£ 3.25 \mathrm{bn} / \mathrm{year}$ and $5 \mathrm{bn} / \mathrm{year}$, while under an $80 \%$ Reduction in GHG Emissions is it generally much higher and between $£ 4.75 \mathrm{bn} / \mathrm{year}$ and $£ 7.5 \mathrm{bn} / \mathrm{year}$

- 2035-2050 period: under the No Climate Policy scenario, investment levels fall to around $£ 1-2 \mathrm{bn} / \mathrm{year}$ and remain $£ 1 \mathrm{bn} / \mathrm{year}$ or less thereafter. Under an $80 \%$ Reduction in GHG Emissions, annual investments do not 
fall down to very low levels after peaking in 2030, but actually stay in the range $£ 1-6 b n / y e a r$.

These findings are consistent with observations made for total cumulative investment found in Section 6.6. They demonstrate that technology pathways under the low carbon scenario have higher investment requirements and that much of the additional investment actually occurs in the period 2030-2050.

Figure $\mathbf{1 5}$ - Comparison of annual investment costs for $\mathbf{U}_{\mathbf{1}}$ and $\mathbf{U}_{\mathbf{2}}$ umbrella scenarios. The boxplots depict mean, $25^{\text {th }}$ and $75^{\text {th }}$ percentiles, upper and lower bound of cumulative investments costs.

U1 No Climate Policy

U2 $80 \%$ Reduction in GHG Emissions
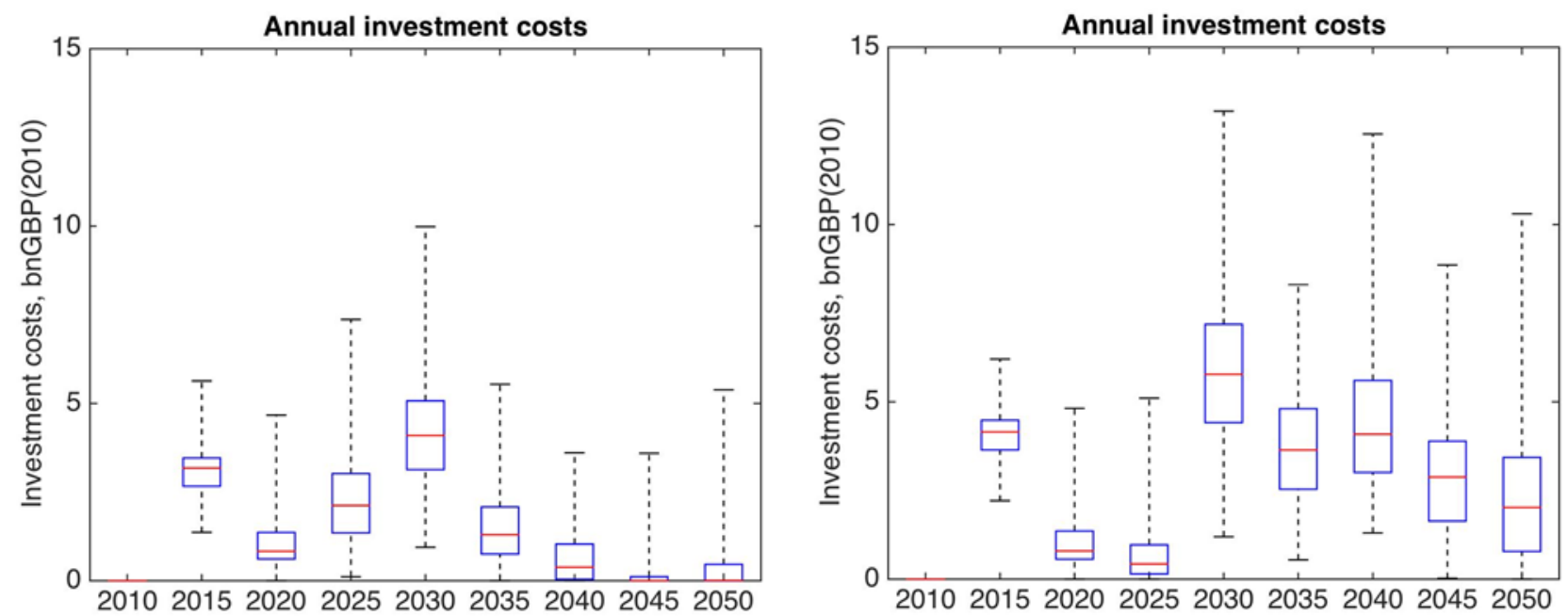

7.0 Discussion

7.1 Comparison with past studies

As highlighted in the introductory framing for this paper (Section 1.0), there is an urgent requirement for countries to develop strategies for deep decarbonisation of their energy systems in line with global agreements on climate change mitigation. In the UK, one of the major policy uncertainties is understanding how much investment needs to be mobilised for the energy transition, particularly in the power sector. Our literature review (Section 3.0) finds that while UK climate targets are for 2050, past estimates of investment requirements to transform the power system have tended to only focus on the 2030 period and to only explore a relatively narrow range of future uncertainties. An important and policy relevant application of energy models is therefore to quantify future investment requirements into the power sector in the period to 2050 and expand the consideration of uncertainty.

This study demonstrates a novel approach that compares and contrasts 800 separate pathways for the UK power sector in the period to 2050, under two different climate policy conditions and a wide range of variations in future technology and cost parameters. This arguably represents the most wide-ranging attempt to consider future uncertainties facing the UK power sector to date, and is undertaken in the context of the decarbonisation of the whole energy system. Our approach goes 
significantly beyond what has been attempted previously in past studies (Section 3.0), each of which, when taken in isolation, only presents a relatively narrow and arguably subjective viewpoint on possible developments rather than revealing the actual broad scope of future possibilities.

The range of annual investment rates found in historical transitions is $\pm 3-11 b n / y e a r$, while estimates from other studies for future investment requirements (when focusing on those figures that cover power generation only, rather than the whole electricity system) are for 2-gbn/year. The annual investment rates shown in Figure 15 illustrate that the outputs from our combined UKTM and D-EXPANSE model assessment spans a comparable range, and slightly beyond (some outlier pathways reach $13 \mathrm{bn}$ /year). The work presented in this paper is therefore consistent with other studies but demonstrates an approach that is able to explain the range of outcomes explored as a function of uncertain technology selection, cost, and policy assumptions.

\section{Implications for policy}

The work presented raises a number of important insights for energy policy in the UK. It first corroborates the findings of other analyses that demonstrate the requirement for a massive investment in new generation capacity if the UK is to meet its 2050 climate targets. The power generation pathways found within the cost-optimal and near-optimal space under stringent climate constraints (the $80 \%$ Reduction in GHG Emissions umbrella scenario) all involved 2050 generation capacities above $100 \mathrm{GW}$, in comparison to pathways found under the No Climate Policy scenario, which featured capacities in the 60-75 GW range (Section 6.5).

We find that, in general terms, a power sector transition pathway to 2050 without any form of GHG emissions policy requires cumulative investments of between $\mathrm{f} 6 \mathrm{obn}$ and $f 75 \mathrm{bn}$. Pathways that meet UK climate policy targets for 2050 on the other hand, require a doubling of cumulative investment requirements to between $f 110$ and f140bn (Section 6.6). The model assessment also gives some insights into the profiling of investments through time. We find that not only are peaks in power sector investment likely to be higher when meeting climate targets, but that a large portion of the difference in future costs occurs from deployment activity in the period 20302050 (Section 6.7).

In terms of technology selection, the analysis across the 800 different modelled pathways demonstrates that there are a very large number of different electricity generation mixes that lie within a relatively small, near-optimal space around the mathematically least cost solution (i.e. $+/-15 \%$ ). Another way of looking at this is that many diverse technological solutions to the energy transition challenge have broadly similar costs. With No Climate Policy, potential for coal-fired power could be as high as $20 \mathrm{GW}$ in 2050, while under an $80 \%$ Reduction in GHG Emissions, the maximum observed deployment was $5 \mathrm{GW}$ (Section 6.4.1). The shift away from unabated coal in many pathways is found to be accompanied by an increased potential for low carbon power generation. Nuclear power, coal CCS, and gas CCS all see their maximum deployment potential increase from around $20 \mathrm{GW}$ under No Climate Policy, to $30 \mathrm{GW}$ when an 80\% Reduction in GHG Emissions is pursued (Sections 6.4.2 and 6.4.3). Other interesting features of many low carbon pathways are an increased preference for 
renewable energy resources (Section 6.4.4) and an increased deployment of power plants traditionally used for system balancing such as open-cycle gas turbines (OCGTs).

What does this diversity in model solutions in the near-optimal space mean for energy policy? Many advanced economies such as the UK have partially or wholly liberalised electricity markets. The UK energy market is dominated by a number of large energy firms, known collectively as the "Big Six" [105]. Only two of these companies are domestically owned, and the UK government itself does not directly own or operate any major parts of the electricity system. Similar market arrangements for the electricity sector can be found in countries as diverse as Germany [106], Spain [107], Chile [108], and Australia [109], while Japan is also observed to be moving in this direction [110]. The official UK Government position is to create the conditions for a market-led transition whereby the best value portfolio of electricity generation emerges from competition [19,23]. As fossil-fuelled technologies currently dominate power generation, a key role for Government is to provide mid-term policy support for low-carbon generation options in order that they can become cost-competitive with these fossil-fuelled technologies. The findings from our study imply that the UK Government's stated policy of maintaining technology neutrality and encouraging market competition in order to drive decarbonisation could be viewed in a positive light $[19,23]$. However, whether or not the UK's current market-led framework will actually able to incentivise investment at the levels required to drive the transition remains to be seen.

The model results illustrate that at least $£ 45 \mathrm{bn}$ will need to be found to replace aging generation plant in the UK whether the Government strives to achieve its ambitious climate targets or not. It is expected that the majority of this capital will be found from the private sector and institutional investors, such as large pension funds. Therefore, it is critical that policymakers seek to create an attractive environment for investment in the period to 2030, and one that can endure thereafter as high annual investment rates need to be sustained to 2050 in the climate-constrained world. This may involve the packaging of investments so that some risks are passed to taxpayers and consumers, making the asset more "investable" for the financier while keeping the overall economic cost to society manageable [24]. Another approach is to explore how new capacity requirements might be met through non-traditional forms of ownership and financing, such as energy co-operatives [111] or energy service companies (ESCOs) [112]. Finally, while a return to complete state ownership of the electricity may seem unlikely in the context of the political preferences of successive UK governments for market-driven solutions [113], it is not impossible to imagine a role for greater state intervention (e.g. as imagined in Foxon [25,114]). Government can potentially borrow at extremely favourable rates and is in a position to take on board significant risk premiums when compared to many private firms, which raises the prospect of the government acting as a guarantor or counterparty for private sector investments [20].

\subsection{Implications for research}

While our specific case study is for the UK, we can draw from our analysis a number of useful insights for studies of deep decarbonisation at the international level. Our work 
shows that the common approach of assessing future investment requirements for energy transitions, which is to use a handful of deterministic scenarios, based on small sets of (at times) minimally varying assumptions, can underplay the extent to which plausible future pathways can differ from one another, even when incurring similar economic costs. This relaxed approach to uncertainty consideration has the effect of disguising the full spectrum of possible futures for policymakers. We find that this effect is present even in studies that use advanced whole energy system models that take into account trade-offs and interactions between diverse parts of the energy economy such as buildings, industry and transport.

While whole system models of this type are useful for exploring "cost-optimal" paths, the fact that they are commonly used with relatively few scenarios (typically <10) means that they risk focusing policymaker attention on the optimal result, which is not necessarily more likely to occur than other near-optimal outcomes, an observation that is well understood in the decision theory community (e.g. see [61]). In complex systems with deep uncertainties it is often argued that a useful application of models is to bound the extremes of the problem space rather than to focus on producing single "optimal" pathways $[63,115,116]$.

Computational limits often preclude the use of whole energy system models with hundreds of scenarios. We propose therefore that whole systems analysis of energy systems may benefit from combined application with detailed sectoral models, and approaches that generate large ensembles of results in order to explore parametric and structural uncertainties. We have demonstrated one such novel approach here by applying our whole system energy optimisation model UKTM in concert with the DEXPANSE model. UKTM provides the whole system overview, while D-EXPANSE performs an advanced sensitivity analysis around the optimal pathways in a single sector, delivering robust insights for policymakers. Researchers undertaking decarbonisation analysis in other countries can benefit from using similar approaches.

Our experience in visualising and interpreting the results of the analysis here is that the use of large pathway ensembles in conjunction with a whole energy systems modelling approach creates large volumes of output data (pathways). This presents its own challenges for analysis and communication of insights [64]. For example, this study shows that the key trends from the analysis cannot be accomplished by using a few deterministic trend lines, but instead involves a "spaghetti" of multiple pathways that can overlap significantly. Many policymakers and indeed, scientists, can find this unsettling, and without guidance may be inclined to believe that the results mean that "anything can happen". Future research on methods to reveal, visualise, interpret, and communicate uncertainties is therefore needed.

There are ongoing efforts to incorporate advanced approaches for searching within high-dimensional results spaces for trends and patterns, such as data clustering techniques and machine learning [117]. For example, these approaches are starting to be used in global-scale climate policy assessments that rely on large pathway ensembles [118]. The extension of these techniques to national level energy policy insights is a logical progression, and the energy research community may well benefit from future developments in this field. As discussed above however, such approaches place an additional burden on both researchers and policymakers to appreciate and plan for uncertainty [119]. Researchers should refer to the existing literature on science-policy communication for guidance in this critical area (e.g. [120]). 


\subsection{Conclusions}

Past investment appraisals of the UK electricity sector transition have considered a relatively narrow range of uncertainties and have focused on the mid-term time horizon to 2030 rather than the climate policy timeframe of 2050 . This paper addressed this gap by exploring an interlinked set of policy, technology and cost uncertainties related to the future UK electricity sector evolution. The analysis linked outputs from a whole energy economy model UKTM (UK TIMES) with the DEXPANSE model that generates large ensembles of cost-optimal and near-optimal UK electricity generation pathways. D-EXPANSE achieves this by combining Monte Carlo analysis with Modelling to Generate Alternatives (MGA). A large ensemble of 800 UK electricity sector pathways was produced, spanning a much broader range of uncertainties than those considered in past published investment appraisals.

The results for the 800 modelled transition pathways show that policies aimed at achieving climate targets are likely to significantly increase the installed capacity required for meeting electricity demand in 2050. With No Climate Policy, installed generation capacities were found in the range $60 \mathrm{GW}-75 \mathrm{GW}$, while under an $80 \%$ Reduction in GHG Emissions, between $100 \mathrm{GW}$ - 130GWof plant were required. Meeting climate targets for 2050 was also found to increase the investment requirements for new electricity generation. The interquartile range for cumulative investments in new generation under the No Climate Policy scenario ranged from $£ 60 \mathrm{bn}-£ 75 \mathrm{bn}$, while under an $80 \%$ Reduction in GHG Emissions, modelled investment requirements approximately double to $£ 110 b n$ - $£ 140 b n$.

An investment profiling assessment shows that capital flows into new electricity generation will likely need to match or exceed historical precedents of $\_3 b n-f 11 b n$ in the period to 2030, regardless of whether or not climate targets are pursued or not. This is driven by the need to replace aging elements of the UK generation fleet that will see their economic lives expire during the 2020's. Post 2030, the decision on whether to achieve climate targets for 2050 or not becomes crucial, because following a climate mitigation pathway implies the need to sustain elevated levels of new plant deployment and investment. With No Climate Policy, investment levels in new generation can fall to around $f 1$ bn annually in the period 2035-2050, while to achieve an $80 \%$ Reduction in GHG Emissions, they need to be sustained at levels of

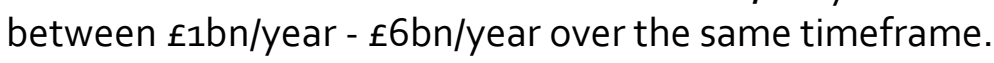

From a policy perspective, our findings align with those of other researchers that identify a pressing need for the UK government to incentivise investment in new lowcarbon generation. The privatised nature of the UK electricity system and the difficulties experienced to date in attracting capital into the sector from traditional sources of financing puts the government in a potentially difficult position. Resolving this policy challenge may require new and innovative models of ownership and financing such as energy co-operatives and energy services companies, and also may require an attractive "packaging" of investments that transfers enough of the risk away from investors to enable capital to flow. Politically, this could be perceived as less than desirable, but the UK government appears to have few alternatives beyond resurrecting the state ownership of energy assets, a concept to which successive UK governments over the last 30 years have demonstrated consistent opposition. 
From a research perspective, this study demonstrates a novel approach that combines a national whole energy systems model with an exploratory pathway generator for delivering policy insights under deep uncertainty. The study shows that adequately expanding the consideration of uncertainty in energy transition modelling leads to large volumes of modelled pathways. Presenting the relevant findings in such a way that the quantitative analysis assists the decision process and does not simply overwhelm policymakers, and indeed researchers, with its complexity, is identified as being crucial to the future use of such approaches. This work also shows that cost minimisation as an approach to making policy decisions on energy transitions has its limitations, and should be augmented or complemented with techniques that tackle high dimensional uncertainties. Grappling with the unknown in long term energy studies is undoubtedly a very challenging exercise, but robust policy insights are unlikely to result from approaches that attempt to minimise, abstract away, or exclude uncertainty from the analysis.

9.0 Glossary

$\begin{array}{ll}\text { BEIS } & \text { UK Department for Business, Energy and Industrial Strategy } \\ \text { CCC } & \text { The UK Committee on Climate Change } \\ \text { CCGT } & \text { Combined Cycle Gas Turbine } \\ \text { CCS } & \text { Carbon Capture and Storage } \\ \text { DECC } & \text { The UK Department of Energy and Climate Change } \\ \text { EFOM } & \text { Energy Flow Optimisation Model } \\ \text { IEA-ETSAP } & \text { The International Energy Agency's Energy Technology Systems } \\ & \text { Analysis Programme } \\ \text { D-EXPANSE } & \text { Dynamic version of EXploration of PAtterns in Near-optimal energy } \\ & \text { ScEnarios } \\ \text { GHG } & \text { Greenhouse Gas } \\ \text { ESOMs } & \text { Energy System Optimisation Models } \\ \text { MARKAL } & \text { MARKet ALlocation Model } \\ \text { MESSAGE } & \text { Model for Energy Supply Systems And their General Environmental } \\ & \text { impact } \\ \text { MGA } & \text { Modelling to Generate Alternatives } \\ \text { OCGT } & \text { Open Cycle Gas Turbine } \\ \text { Ofgem } & \text { UK Office of Gas and Electricity Markets } \\ \text { OSEMoSYS } & \text { Open Source Energy Modelling System } \\ \text { PV } & \text { Photovoltaics } \\ \text { TIMES } & \text { The Integrated MARKAL-EFOM System } \\ \text { UKTM } & \text { UK TIMES Model }\end{array}$

\subsection{Acknowledgements}

Francis G.N. Li was supported by the UK Engineering and Physical Sciences Research Council (EPSRC) under the Realising Transition Pathways project (Grant EP/Ko05316/1) and the Whole Systems Energy Modelling Consortium (WholeSEM, Grant EP/Ko39326/1). For the development of the D-EXPANSE model, Evelina Trutnevyte was supported by the Realising Transition Pathways project of the UK Engineering and Physical Sciences Research Council (Grant EP/Koo5316/1), the 
ClimPol project of the Competence Center for Environment and Sustainability at ETH Zurich, the Swiss Competence Center for Energy Research-Supply of Electricity, and the Swiss National Science Foundation Ambizione Energy grant (Grant 160563). The authors would like to thank Steve Pye, who provided detailed model output data from past UK decarbonisation pathway studies, and the two anonymous reviewers whose constructive criticism and feedback helped to improve the quality of the final paper.

\section{$11.0 \quad$ References}

[1] UNFCCC. Adoption of the Paris Agreement: Proposal by the President: Draft decision -/CP.21. United Nations Framework Convention on Climate Change (UNFCCC): 2015.

[2] Shi J, Chen W, Yin X. Modelling building's decarbonization with application of China TIMES model. Appl Energy 2016;162:1303-12. doi:10.1016/j.apenergy.2015.06.056.

[3] Zhang $\mathrm{H}$, Chen W, Huang W. TIMES modelling of transport sector in China and USA: Comparisons from a decarbonization perspective. Appl Energy 2016;162:1505-14. doi:10.1016/j.apenergy.2015.08.124.

[4] Williams JH, DeBenedictis A, Ghanadan R, Mahone A, Moore J, Morrow WR, et al. The Technology Path to Deep Greenhouse Gas Emissions Cuts by 2050: The Pivotal Role of Electricity. Science (80- ) 2012;335:53-9. doi:10.1126/science.1208365.

[5] Palzer A, Henning H-M. A comprehensive model for the German electricity and heat sector in a future energy system with a dominant contribution from renewable energy technologies - Part II: Results. Renew Sustain Energy Rev 2014;30:1019-34. doi:10.1016/j.rser.2013.11.032.

[6] Lund $\mathrm{H}$, Mathiesen BV. Energy system analysis of $100 \%$ renewable energy systems-The case of Denmark in years 2030 and 2050. Energy 2009;34:52431. doi:10.1016/j.energy.2008.04.003.

[7] Daly HE, Ramea K, Chiodi A, Yeh S, Gargiulo M, Gallachóir BÓ. Incorporating travel behaviour and travel time into TIMES energy system models. Appl Energy 2014;135:429-39. doi:10.1016/j.apenergy.2014.08.051.

[8] Pattupara R, Kannan R. Alternative low-carbon electricity pathways in Switzerland and it's neighbouring countries under a nuclear phase-out scenario. Appl Energy 2016;172:152-68. doi:10.1016/j.apenergy.2016.03.084.

[9] Fortes P, Alvarenga A, Seixas J, Rodrigues S. Long-term energy scenarios: Bridging the gap between socio-economic storylines and energy modeling. Technol Forecast Soc Change 2015;91:161-78. doi:10.1016/j.techfore.2014.02.006.

[10] Pye S, Daly H. Modelling sustainable urban travel in a whole systems energy model. Appl Energy 2015;159:97-107. doi:10.1016/j.apenergy.2015.08.127.

[11] Fais B, Sabio N, Strachan N. The critical role of the industrial sector in reaching long-term emission reduction, energy efficiency and renewable targets. Appl Energy 2016;162:699-712. doi:10.1016/j.apenergy.2015.10.112.

[12] HM Government. Climate Change Act 2008. London, UK: HMSO; 2008.

[13] CCC. The Fifth Carbon Budget: The next step towards a low-carbon economy. The Committee on Climate Change (CCC), London, UK: 2015. 
[14] Strachan N, Kannan R. Hybrid modelling of long-term carbon reduction scenarios for the UK. Energy Econ 2008;30:2947-63.

doi:10.1016/j.eneco.2008.04.009.

[15] Pye S, Sabio N, Strachan N. An integrated systematic analysis of uncertainties in UK energy transition pathways. Energy Policy $2015 ; 87: 673-84$.

doi:10.1016/j.enpol.2014.12.031.

[16] Ekins P, Strachan N, Keppo I, Usher W, Skea J, Anandarajah G. UKERC Research Report: The UK Energy System in 2050: Comparing Low-Carbon, Resilient Scenarios. UK Energy Research Centre (UKERC), London, UK: 2013.

[17] CCC. Building a low-carbon economy - the UK's contribution to tackling climate change. The Committee on Climate Change (CCC), London, UK: 2008.

[18] DECC. The UK Low Carbon Transition Plan: National Strategy for Climate and Energy. London, UK: 2009.

[19] HM Government. The Carbon Plan: Delivering Our Low Carbon Future. London, UK: 2011.

[20] Trutnevyte E, Strachan N, Dodds PE, Pudjianto D, Strbac G. Synergies and trade-offs between governance and costs in electricity system transition. Energy Policy 2015;85:170-81. doi:10.1016/j.enpol.2015.06.003.

[21] National Grid. Future Energy Scenarios: Gas and Electricity Transmission. National Grid, London: 2013.

[22] Watson J, Gross R, Ketsopoulou I, Winskel M. The impact of uncertainties on the UK's medium-term climate change targets. Energy Policy 2015;87:685-95. doi:10.1016/j.enpol.2015.02.030.

[23] DECC. Electricity Market Reform: Policy Overview. UK Department of Energy and Climate Change (DECC), London, UK: 2012.

[24] Bolton R, Foxon TJ, Hall S. Energy transitions and uncertainty: Creating low carbon investment opportunities in the UK electricity sector. Environ Plan C Gov Policy 2015. doi:10.1177/0263774X15619628.

[25] Foxon TJ. Transition pathways for a UK low carbon electricity future. Energy Policy 2013;52:10-24. doi:10.1016/j.enpol.2012.04.001.

[26] Usher W, Strachan N. An expert elicitation of climate, energy and economic uncertainties. Energy Policy 2013;61:811-21. doi:10.1016/j.enpol.2013.06.110.

[27] Harris G, Heptonstall P, Gross R, Handley D. Cost estimates for nuclear power in the UK, ICEPT Working Paper (ICEPT/WP/2012/014). Imperial College Centre for Energy Policy and Technology (ICEPT), London, UK: 2012.

[28] Corner A, Venables D, Spence A, Poortinga W, Demski C, Pidgeon N. Nuclear power, climate change and energy security: Exploring British public attitudes. Energy Policy 2011;39:4823-33. doi:10.1016/j.enpol.2011.06.037.

[29] CCC. The 2050 target - achieving an $80\{\%\}$ reduction including emissions from international aviation and shipping. Committee on Climate Change (CCC), London UK: 2012.

[30] Radgen P, Irons R, Schoenmakers H. Too Early or Too Late for CCS-What Needs to be Done to Overcome the Valley of Death for Carbon Capture and Storage in Europe? Energy Procedia 2013;37:6189-201. doi:10.1016/j.egypro.2013.06.548.

[31] Chalmers H, Gibbins J, Gross R, Haszeldine S, Heptonstall P, Kern F, et al. Analysing Uncertainties for CCS: From Historical Analogues to Future Deployment Pathways in the UK. Energy Procedia 2013;37:7668-79. doi:10.1016/j.egypro.2013.06.712.

[32] House Of Commons Energy and Climate Change Committee. Future of carbon 
capture and storage in the UK: Second report of session 2015-16. House of Commons, London, UK: 2016.

[33] Pye S, Usher W, Strachan N. The uncertain but critical role of demand reduction in meeting long-term energy decarbonisation targets. Energy Policy 2014;73:575-86. doi:10.1016/j.enpol.2014.05.025.

[34] Usher W. The Value of Global Sensitivity Analysis for Energy System Modelling. 34th Int. Energy Work. (IEW 2015), Abu Dhabi, UAE: 2015.

[35] Slade R, Baven A, Gross R. The UK bio-energy resource base to 2050: estimates, assumptions, and uncertainties (UKERC/WP/TPA/2010/002). Imperial Centre for Energy Policy and Technology and the UK Energy Research Centre (UKERC), London: 2010.

[36] Slade R, Bauen A, Gross R. Global bioenergy resources. Nat Clim Chang 2014;4:99-105. doi:10.1038/nclimate2097.

[37] Usher W, Strachan N. Critical mid-term uncertainties in long-term decarbonisation pathways. Energy Policy 2012;41:433-44. doi:10.1016/j.enpol.2011.11.004.

[38] Fuss S, Canadell JG, Peters GP, Tavoni M, Andrew RM, Ciais P, et al. Betting on negative emissions. Nat Clim Chang 2014;4:850-3. doi:10.1038/nclimate2392.

[39] Lockwood M. The political sustainability of climate policy: The case of the UK Climate Change Act. Glob Environ Chang 2013;23:1339-48. doi:10.1016/j.gloenvcha.2013.07.001.

[40] Ekins P. An Economic Perspective on Technological Transitions Related to Energy and Climate Change, with a Case Study of the UK. Econ Polit 2010;2:247-76. doi:10.1428/32539.

[41] Blyth W, McCarthy R, Gross R. Financing the Power Sector: Is the Money Available? UK Energy Research Centre (UKERC), London, UK: 2014.

[42] BNEF. UK Big 6 Utility Investment Trends: A report for Greenpeace UK on the generation investments of the Big 6 utilities. Bloomberg New Energy Finance: 2012.

[43] Ofgem. Project Discovery Energy Market Scenarios. Office of Gas and Electricity Markets (Ofgem), London, UK: 2009.

[44] Ofgem. Project Discovery: Energy Market Scenarios Update. Office of Gas and Electricity Markets (Ofgem), London, UK: 2010.

[45] Ofgem. Project Discovery: Options for delivering secure and sustainable energy supplies. Office of Gas and Electricity Markets (Ofgem), London, UK: 2010.

[46] DECC. Updated energy and emissions projections 2012. UK Department of Energy and Climate Change (DECC), London, UK: 2012.

[47] LSE. Energy and the Economy: The 2030 Outlook for UK Businesses. A Report Commissioned by RWE npower. The London School of Economics and Political Science (LSE), London, UK: 2012.

[48] Ernst \& Young. Securing the UK's energy future — seizing the investment opportunity. Ernst \& Young, London, UK: 2009.

[49] CCC. Next steps on Electricity Market Reform - securing the benefits of lowcarbon investment. Committee on Climate Change (CCC), London UK: 2013.

[50] DECC. Delivering UK Energy Investment. UK Department of Energy and Climate Change (DECC), London, UK: 2015.

[51] Pöyry. Technology supply curves for low-carbon power generation. 2013.

[52] Alcamo J. Chapter Six The SAS Approach: Combining Qualitative and Quantitative Knowledge in Environmental Scenarios. In: Alcamo J, editor. 
Environ. Futur. Pract. Environ. Scenar. Anal., vol. 2, Elsevier; 2008, p. 123-50. doi:10.1016/S1574-101X(08)00406-7.

[53] CCC. Bioenergy Review. The Committee on Climate Change (CCC), London, UK: 2011.

[54] Taylor PG, Upham P, McDowall W, Christopherson D. Energy model, boundary object and societal lens: 35 years of the MARKAL model in the UK. Energy Res Soc Sci 2014;4:32-41. doi:10.1016/j.erss.2014.08.007.

[55] Strachan N, Fais B, Daly H. Reinventing the energy modelling-policy interface. Nat Energy 2016;1:16012. doi:10.1038/nenergy.2016.12.

[56] Kriegler E, Riahi K, Bauer N, Schwanitz VJ, Petermann N, Bosetti V, et al. Making or breaking climate targets: The AMPERE study on staged accession scenarios for climate policy. Technol Forecast Soc Change 2015;90:24-44. doi:10.1016/j.techfore.2013.09.021.

[57] Loulou R, Labriet M. ETSAP-TIAM: the TIMES integrated assessment model Part I: Model structure. Comput Manag Sci 2008;5:7-40. doi:10.1007/s10287007-0046-z.

[58] Howells M, Rogner H, Strachan N, Heaps C, Huntington H, Kypreos S, et al. OSeMOSYS: The Open Source Energy Modeling System. Energy Policy 2011;39:5850-70. doi:10.1016/j.enpol.2011.06.033.

[59] Keppo I, Strubegger M. Short term decisions for long term problems - The effect of foresight on model based energy systems analysis. Energy 2010;35:2033-42. doi:10.1016/j.energy.2010.01.019.

[6o] Li FGN, Strachan N. Modelling energy transitions for climate targets under landscape and actor inertia. Environ Innov Soc Transitions 2016. doi:10.1016/j.eist.2016.08.002.

[61] Lempert RJ, Popper SW, Bankes SC. Shaping the Next One Hundred Years: New Methods for Quantitative, Long-Term Policy Analysis. RAND report MR1626. RAND Corporation, The RAND Pardee Center, Santa Monica, CA, USA: RAND Corporation; 2003.

[62] Rosenhead J, Elton M, Gupta SK. Robustness and Optimality as Criteria for Strategic Decisions. Oper Res Q 1972;23:413. doi:10.2307/3007957.

[63] Trutnevyte E. Does cost optimization approximate the real-world energy transition? Energy 2016. doi:0.1016/j.energy.2016.03.038.

[64] Trutnevyte E, Guivarch C, Lempert R, Strachan N. Reinvigorating the scenario technique to expand uncertainty consideration. Clim Change 2016;135:373-9. doi:10.1007/s10584-015-1585-x.

[65] van 't Klooster SA, van Asselt MBA. Practising the scenario-axes technique. Futures 2006;38:15-30. doi:10.1016/j.futures.2005.04.019.

[66] Theodoridis S. Monte Carlo Methods. Mach. Learn., Elsevier; 2015, p. 707-44. doi:10.1016/B978-0-12-801522-3.00014-8.

[67] Chang S-Y, Brill ED, Hopkins LD. Use of mathematical models to generate alternative solutions to water resources planning problems. Water Resour Res 1982;18:58-64. doi:10.1029/WR018ioo1pooo58.

[68] DeCarolis JF. Using modeling to generate alternatives (MGA) to expand our thinking on energy futures. Energy Econ 2011;33:145-52. doi:10.1016/j.enec0.2010.05.002.

[69] Price J, Keppo I. Modelling to generate alternatives: A technique to explore uncertainty in energy-environment-economy models. 35th Int. Energy Work. (IEW 2016), Cork, Ireland: 2016.

[70] Trutnevyte E. EXPANSE methodology for evaluating the economic potential of 
renewable energy from an energy mix perspective. Appl Energy 2013;111:593601. doi:10.1016/j.apenergy.2013.04.083.

[71] Loulou R, Remne U, Kanudia A, Lehtila A, Goldstein G. Documentation for the TIMES Model. International Energy Agency Energy Technology Systems Analysis Programme (IEA-ETSAP): 2005.

[72] Loulou R, Remme U, Kanudia A, Lehtila A, Goldstein G. Documentation for the TIMES model, Part II. 2005.

[73] Kannan R, Strachan N, Pye S, Anandarajah G, Balta-Ozkan N. UK MARKAL Model Documentation. London, UK: 2007.

[74] Strachan N, Kannan R, Pye S. Scenarios and Sensitivities on Long-term UK Carbon Reductions using the UK MARKAL and MARKAL-Macro Energy System Models. UK Energy Research Centre (UKERC), London, UK: 2008.

[75] Strachan N, Pye S, Hughes N. The role of international drivers on UK scenarios of a low-carbon society. Clim Policy 2008;8:S125--S139. doi:10.3763/cpol.2007.0489.

[76] Kannan R, Strachan N. Modelling the UK residential energy sector under longterm decarbonisation scenarios: Comparison between energy systems and sectoral modelling approaches. Appl Energy 2009;86:416-28. doi:10.1016/j.apenergy.2008.08.005.

[77] Jablonski S, Strachan N, Brand C, Baven A. The role of bioenergy in the UK's energy future formulation and modelling of long-term UK bioenergy scenarios. Energy Policy 2010;38:5799-816. doi:10.1016/j.enpol.2010.05.031.

[78] Ekins P, Anandarajah G, Strachan N. Towards a low-carbon economy: scenarios and policies for the UK. Clim Policy 2011;11:865-82. doi:10.3763/cpol.2010.0126.

[79] McDowall W, Anandarajah G, Dodds PE, Tomei J. Implications of sustainability constraints on UK bioenergy development: Assessing optimistic and precautionary approaches with UK MARKAL. Energy Policy 2012;47:424-36. doi:10.1016/j.enpol.2012.05.015.

[80] CCC. The Fourth Carbon Budget: Reducing Emissions through the 2020s. The Committee on Climate Change (CCC), London, UK: 2010.

[81] DECC. The UK Low Carbon Transition Plan: Analytical Annex. 2010.

[82] Pye S, Anandarajah G, Fais B, McGlade C, Strachan N. Pathways to Deep Decarbonization in the United Kingdom. IDDRI, SDSN and UCL Energy Institute: 2015.

[83] Daly HE, Dodds PE, Fais B. The UK TIMES Model: UKTM Documentation. UCL Energy Institute, London, UK: 2014.

[84] Hourcade J-C, Jaccard M, Bataille C, Ghersi F. Hybrid Modeling: New Answers to Old Challenges Introduction to the Special Issue of The Energy Journal. Energy J 2006;SI2006. doi:10.5547/ISSN0195-6574-EJ-VolSI2006-NoSI2-1.

[85] Trutnevyte E, Barton J, O'Grady Á, Ogunkunle D, Pudjianto D, Robertson E. Linking a storyline with multiple models: A cross-scale study of the UK power system transition. Technol Forecast Soc Change 2014;89:26-42. doi:10.1016/j.techfore.2014.08.018.

[86] Lund H. Renewable Energy Systems: A Smart Energy Systems Approach to the Choice and Modeling of 100\% Renewable Solutions, 2nd Edition. Elsevier; 2014.

[87] Mathiesen BV, Lund H, Connolly D, Wenzel H, Østergaard PA, Möller B, et al. Smart Energy Systems for coherent 100\% renewable energy and transport solutions. Appl Energy 2015;145:139-54. doi:10.1016/j.apenergy.2015.01.075. 
[88] Lund PD, Lindgren J, Mikkola J, Salpakari J. Review of energy system flexibility measures to enable high levels of variable renewable electricity. Renew Sustain Energy Rev 2015;45:785-807. doi:10.1016/j.rser.2015.01.057.

[89] OBR. Fiscal sustainability report - July 2012. UK Office for Budget Responsibility (OBR), London, UK: 2012.

[90] ONS. National Population Projections, 2010-Based Statistical Bulletin. UK Office of National Statistics (ONS), Newport, UK: 2011.

[91] DECC. Carbon Valuation in UK Policy Appraisal: A Revised Approach. London, UK: 2009.

[92] DECC. Quarterly Energy Prices December 2012 (URN: 12D/276d). UK Department of Energy and Climate Change (DECC), London, UK: 2012.

[93] Parsons Brinckearhoff. Electricity Generation Model - 2013 Update of NonRenewable Technologies. Parsons Brinckerhoff Manchester Technology Centre, Manchester, UK: 2013.

[94] Parsons Brinckerhoff. Electricity Generation Costs Model: 2013 Update of Renewable Technologies. Parsons Brinckerhoff, Newcastle, UK: 2013.

[95] Arup. Review of the Generation Costs and Deployment Potential of Renewable Electricity Technologies in the UK. London, UK: 2011.

[96] DECC. Energy consumption in the United Kingdom: 2011 - Overall energy consumption in the UK since 1970 (Publication URN 11D/806). UK Department of Energy and Climate Change (DECC), London, UK: 2011.

[97] DECC. Digest of United Kingdom Energy Statistics (DUKES) 2015. Department of Energy and Climate Change (DECC), London, UK: 2015.

[98] Royal Academy of Engineering. GB electricity capacity margin. The Royal Academy of Engineering, London, UK: 2013.

[99] HM Treasury. The Green Book: Appraisal and Evaluation in Central Government. London, UK: 2011.

[100] Anandarajah G, Strachan N, Ekins P, Kannan R, Hughes N. Pathways to a Low Carbon Economy: Energy Systems Modelling. UK Energy Research Centre (UKERC), London, UK: 2009.

[101] Ekins P, Keppo I, Skea J, Strachan N, Usher W, Anandarajah G. The UK energy system in 2050: comparing low-carbon, resilient scenarios. UK Energy Research Centre (UKERC), London, UK: UK Energy Research Centre; 2013.

[102] Usher W, Strachan N. UK MARKAL Modelling - Examining Decarbonisation Pathways in the 2020 s on the Way to Meeting the 2050 Emissions Target: Final Report for the Committee on Climate Change (CCC). London, UK: 2010.

[103] AEA. Pathways to 2050 - Detailed Analyses: MARKAL Model Review and Scenarios for DECC's 4th Carbon Budget Evidence Base. AEA Technology Plc, London, UK: 2011.

[104] Tietje O. Identification of a small reliable and efficient set of consistent scenarios. Eur J Oper Res 2005;162:418-32. doi:10.1016/j.ejor.2003.08.054.

[105] Thomas S. A perspective on the rise and fall of the energy regulator in Britain. Util Policy 2016;39:41-9. doi:10.1016/j.jup.2016.02.004.

[106] Müsgens F, Ockenfels A, Peek M. Economics and design of balancing power markets in Germany. Int J Electr Power Energy Syst 2014;55:392-401. doi:10.1016/j.ijepes.2013.09.020.

[107] Ciarreta A, Nasirov S, Silva C. The development of market power in the Spanish power generation sector: Perspectives after market liberalization. Energy Policy 2016;96:700-10. doi:10.1016/j.enpol.2016.06.029.

[108] del Sol P. Responses to electricity liberalization: the regional strategy of a 
Chilean generator. Energy Policy 2002;30:437-46. doi:10.1016/So3014215(01)00112-4.

[109] Nepal R, Menezes F, Jamasb T. Network regulation and regulatory institutional reform: Revisiting the case of Australia. Energy Policy 2014;73:259-68. doi:10.1016/j.enpol.2014.05.037.

[110] Goto M, Sueyoshi T. Electric power market reform in Japan after Fukushima Daiichi nuclear plant disaster. Int J Energy Sect Manag 2015;9:336-6o. doi:10.1108/IJESM-05-2014-0009.

[111] Yildiz Ö. Financing renewable energy infrastructures via financial citizen participation - The case of Germany. Renew Energy 2014;68:677-85. doi:10.1016/j.renene.2014.02.038.

[112] Bolton R, Foxon TJ. A socio-technical perspective on low carbon investment challenges - Insights for UK energy policy. Environ Innov Soc Transitions 2015;14:165-81. doi:10.1016/j.eist.2014.07.005.

[113] Pollitt MG. The role of policy in energy transitions: Lessons from the energy liberalisation era. Energy Policy 2012;50:128-37. doi:10.1016/j.enpol.2012.03.004.

[114] Foxon TJ, Hammond GP, Pearson PJG. Developing transition pathways for a low carbon electricity system in the UK. Technol Forecast Soc Change 2010;77:1203-13. doi:10.1016/j.techfore.2010.04.002.

[115] Bankes S. Exploratory Modeling for Policy Analysis. Oper Res 1993;41:435-49. doi:10.1287/opre.41.3.435.

[116] Schweizer VJ, Morgan MG. Bounding US electricity demand in 2050. Technol Forecast Soc Change 2016;105:215-23. doi:10.1016/j.techfore.2015.09.001.

[117] Kwakkel JH, Auping WL, Pruyt E. Dynamic scenario discovery under deep uncertainty: The future of copper. Technol Forecast Soc Change 2013;80:789800. doi:10.1016/j.techfore.2012.09.012.

[118] Rozenberg J, Guivarch C, Lempert R, Hallegatte S. Building SSPs for climate policy analysis: a scenario elicitation methodology to map the space of possible future challenges to mitigation and adaptation. Clim Change 2014;122:509-22. doi:10.1007/s10584-013-0904-3.

[119] Stirling A. Keep it complex. Nature 2010;468:1029-31. doi:10.1038/4681029a.

[120] Morgan MG, Dowlatabadi H, Henrion M, Keith D, Lempert R, McBride S, et al. Best practice approaches for characterizing, communicating, and incorporating scientific uncertainty in decisionmaking. U.S. Climate Change Science Program (CCSP): 2009 . 